\title{
RMetS
}

Royal Meteorological Society

\section{Process-oriented large-eddy simulations of a midlatitude cirrus cloud system based on observations}

\author{
Ingo Sölchªnd Bernd Kärcher \\ Deutsches Zentrum für Luft- und Raumfahrt, Oberpfaffenhofen, Germany \\ ${ }^{*}$ Correspondence to: I. Sölch, Deutsches Zentrum für Luft- und Raumfahrt, Institut für Physik der Atmosphäre, \\ Oberpfaffenhofen, Wessling, Germany 82230. E-mail: ingo.soelch@dlr.de
}

We apply a cloud-resolving model with explicit aerosol and ice microphysics and Lagrangian ice particle tracking to simulate the evolution of a cirrus cloud field observed during the US Atmospheric Radiation Measurement Program Intensive Operational Period in March 2000. This comprehensive data set includes remote sensing, radiosonde, and aircraft measurements of a midlatitude cirrus cloud system, supported by estimates of the dynamical cloud forcing. The dataset allows us to evaluate and study in great detail the process-oriented representation of the microphysical processes relevant to the formation and evolution of deep, stratiform cirrus (in particular ice crystal sedimentation and aggregation). The suite of explicitly resolved physical processes in our model enables us to better understand the sensitivity of the simulated cirrus properties on a large number of microphysical and environmental parameters.

The evolution of the domain-integrated cloud optical depth is largely dominated by homogeneous freezing processes. We find that the evolution of the observed cirrus cloud system is most dependent on updraught speed and ice supersaturation and that homogeneous freezing leads to a total, cloud-averaged ice crystal concentration of $0.1 \mathrm{~cm}^{-3}$ of air. It is not necessary to invoke heterogeneous ice nuclei to explain most of the data, but we cannot rule out that a small concentration (up to $0.002 \mathrm{~cm}^{-3}$ ) of such particles may have affected the cirrus cloud field in nature. Cloud-averaged ice particle size distributions are bimodal, separating two distinct growth regimes in the developed cloud. The small mode (ice particle sizes below a few $100 \mu \mathrm{m}$ ) forms by homogeneous freezing of supercooled aerosol droplets and grows by deposition of water molecules from the gas phase. The large mode (sizes up to several $1000 \mu \mathrm{m}$ ) forms and grows by aggregation. We demonstrate that the formation of the largest crystals by aggregation in deep cirrus is controlled in part by the nucleation of new ice crystals in dynamically active, highly supersaturated upper cloud regions. Furthermore, a pronounced increase in the number of aggregation events is predicted in sublimation zones. The combined effect of sublimation and sedimentation leads to the formation of a very thin (vertical extension $\sim 100 \mathrm{~m}$ ) sublimation microlayer mainly composed of aggregated ice crystals, containing relatively high total ice crystal number concentrations $\left(\sim 0.02 \mathrm{~cm}^{-3}\right)$ comparable to those generated locally by homogeneous freezing in the upper cloud layers. Copyright (c) 2011 Royal Meteorological Society

\footnotetext{
Key Words: cloud-resolving model; ice microphysics; observation case-study; ARM

Received 8 July 2010; Revised 6 December 2010; Accepted 7 December 2010; Published online in Wiley Online Library

Citation: Sölch I, Kärcher B. 2011. Process-oriented large-eddy simulations of a midlatitude cirrus cloud system based on observations. Q. J. R. Meteorol. Soc. 137: 374-393. DOI:10.1002/qj.764
}

\section{Introduction}

In Figure 1 we depict various processes and the associated spatial and temporal scales that contribute to the atmospheric effects of cirrus clouds. We also highlight modelling approaches to simulate cirrus. Cirrus genesis involves the smallest scales, where micrometre-sized aerosols - airborne solid or supercooled liquid solution particles with 
a multitude of chemical components - nucleate pristine ice crystals within seconds to minutes. Cirrus with pristine ice crystal size distributions in the size range $1-100 \mu \mathrm{m}$ may evolve into large precipitating cloud fields in ice supersaturated regions via water vapour deposition as well as aggregation of ice crystals, influenced by atmospheric motions on a wide array of spatial and temporal scales (Kärcher and Spichtinger, 2009). Important questions include how these processes determine the small-scale variability of cirrus cloud properties and which of them need to be considered explicitly in parametrizations of cirrus radiative effects and microphysics (Lynch et al., 2002) to inform large-scale models. The cloud-resolving large-eddy cirrus model EULAG-LCM described in detail in Sölch and Kärcher (2010) (hereafter SK10) operates on intermediate spatial scales (horizontally $\mathcal{O}(10 \mathrm{~km})$, vertically $\mathcal{O}(100 \mathrm{~m}))$ and time-scales $\mathcal{O}(1 \mathrm{~h})$, and therefore bridges the gap between the smaller (microscopic) and larger (synoptic and planetary) scales.

With the advent of more sophisticated cloud-resolving models, the need for comprehensive observational datasets increases in order to validate such simulations. In turn, more detailed, validated models are needed to fully analyse such measurements and to fully understand the implications raised by the data. In the past, both cirrus observations and the related modelling exercises have been found to be very challenging (Jensen et al., 1994, 2004; Raschke et al., 1998). The ongoing GCSS* brings together members of the observational and modelling communities. Within this organisational framework, these groups strive for a better understanding of the physics of cloud systems important to the Earth's climate. In particular, the GCSS (http://www.gewex.org/gcss.html) WG 2 initiated a new cirrus cloud model intercomparison case-study. A number of international research teams employ several different multi-dimensional cloud-resolving models and share their results and expertise within WG 2 .

The most recent WG2 simulations have been based on observations of a regional-scale cirrus cloud system, performed during the ARM Program IOP in northern Oklahoma, USA, in March 2000. Ongoing efforts in the WG 2 concentrate on modelling the initiation and dissipation of the first, optically thin cirrus clouds observed from the ground on the local morning of 9 March 2000. In the present study, we go one step further and investigate the further development (over $4 \mathrm{~h}$ ) of the cirrus cloud field, observed $4 \mathrm{~h}$ later at the ARM CF site, Lamont, Oklahoma, in the southern Great Plains. We thereby extend the WG2 analysis to the later stages of the cirrus life cycle, when the cirrus cloud increased considerably in vertical extension and optical depth.

The comprehensive ARM IOP dataset is used to constrain and evaluate the present simulations. It combines groundbased lidar and radar observations with aircraft in situ measurements, radiosonde data, and estimates of the dynamical cloud forcing. It enables us to (i) evaluate the representation of the full range of ice-related microphysical processes in the EULAG-LCM when coupled to the turbulent flow field and (ii) study the composition and evolution of a representative midlatitude cirrus cloud system in great detail. The model results provide further insights into

*Acronyms and abbreviations are given in Appendix A. the mechanisms responsible for the formation of large (millimetre-sized) ice crystal aggregates in deep, stratiform cirrus. Such ice particles are important, because they impact the upper tropospheric water budget by contributing to the vertical flux of cloud ice water mass and may seed lower-level clouds composed of supercooled water drops and thereby initiate glaciation and the formation of precepitation (Hall and Pruppacher, 1976), particularly at midlatitudes.

As a motivation, Figure 2 shows the temporal evolution of the mean cloud (domain-integrated) ice water path, $\overline{\mathrm{IWP}}$, and effective diameter, $\bar{D}_{\text {eff }}$, simulated by the EULAG-LCM. The resulting evolution of the short wave optical depth is discussed later in this study by means of Figure 12. The values attained after $1-2 \mathrm{~h}$ of evolution are typical for regionalscale midlatitude cirrus clouds, consistent with satellite and aircraft data (Stubenrauch et al., 2004; Liou et al., 2008). Additionally, Figure 3 depicts the two-dimensional (2D) distribution of the ice water sedimentation mass flux along with contours of the mean maximum ice crystal dimension, and ice crystal terminal fall speeds with contours of the ice saturation ratio, for the cirrus cloud system at about 50 and 66 min after formation.

Within only $16 \mathrm{~min}$, the cloud vertical thickness increases from $\sim 0.5$ to $\sim 1 \mathrm{~km}$. In the upper cloud region, where high supersaturations $(\sim 40 \%$, or ice saturation ratio $S_{\mathrm{i}} \simeq 1.4$, equivalent to a relative humidity over ice of $140 \%$ ) prevail, favouring homogeneous freezing, ice crystals stay relatively small (mean maximum dimensions $D<50 \mu \mathrm{m}$ ). The supersaturation stays high because there is a continuous uplift and the nucleated ice crystals sediment into less supersaturated, lower levels. The cloud is close to saturation (bold solid contours in Figures $3(\mathrm{~b}, \mathrm{~d})$ ) at about $8 \mathrm{~km}$ altitude, below which the air is very dry $\left(S_{\mathrm{i}}=0.6\right)$, but becomes moister again at lower altitudes $\left(S_{\mathrm{i}}=0.8\right)$. In the upper parts of the subsaturated regions, mean maximum dimensions can be large $(D=250 \mu \mathrm{m})$, indicating that ice crystals entered these regions by sedimentation. Some of the large crystals have been able to fall through this sublimation layer between 50 and $66 \mathrm{~min}$. Their maximum dimensions decreased to values of $100 \mu \mathrm{m}$ or less. It is well known from in situ observations that cirrus ice particles with low ice water content may be present in interstitial, subsaturated regions (Ström et al., 2003).

Several fall streaks are evident (especially after $66 \mathrm{~min}$ ), indicated by the yellow shading, both from ice mass flux, $\Phi$, and terminal fall speed, $v_{\mathrm{t}}$. However, the fall streaks associated with these two quantities are not identical, i.e. the highest $\Phi$ values do not always correspond to the hightest $v_{\mathrm{t}}$ values. This is because $\Phi$ and $v_{\mathrm{t}}$ probe different moments of the ice PSD, with $\Phi$ being most sensitive to the largest crystals, which are present only in very low number concentrations. We will discuss the PSDs and the physical mechanisms responsible for the generation of large ice crystals in the present work.

Section 2 briefly recalls the main features of the EULAGLCM model system from SK10. In section 3, we sketch the observational basis of our simulations - the ARM IOP 9 March 2000 case-study - followed by a description of the simulation set-up (section 4). We compare observed and simulated cloud properties in section 5 . We address the origin and life cycle of large ice crystal aggregates in section 6 and describe numerous sensitivity studies in section 7 , investigating the sensitivity of the simulation results to uncertainties in the numerical set-up, the microphysical 


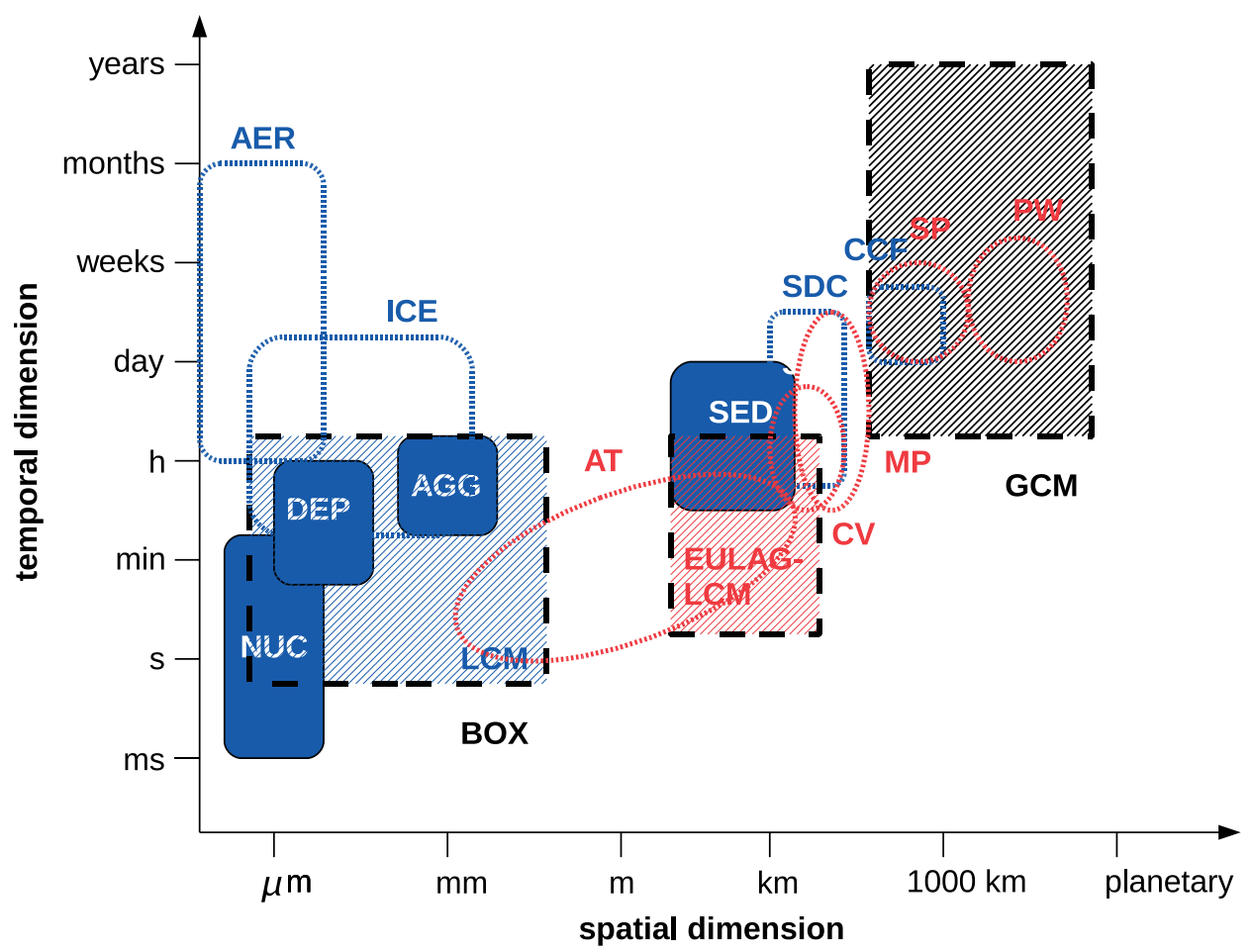

Figure 1. Typical scales of atmospheric motions (red ellipses), cloud structures (blue squares) and microphysical processes (filled blue boxes). AT-atmospheric turbulence; CV-convection; MP-mesoscale processes; SP-synoptic-scale processes; PW-planetary waves; AER-aerosol particles; ICE-ice crystals; SDC-single detached clouds; CCF-cirrus cloud fields; NUC-ice nucleation; DEP-depositional growth; AGG-aggregation; SED-sedimentation. Dashed black boxes represent typical resolution and domain sizes of different model approaches: BOX-box or parcel models; LCM-the Lagrangian Cirrus Module (SK10); GCM-general circulation (global weather or climate) models.

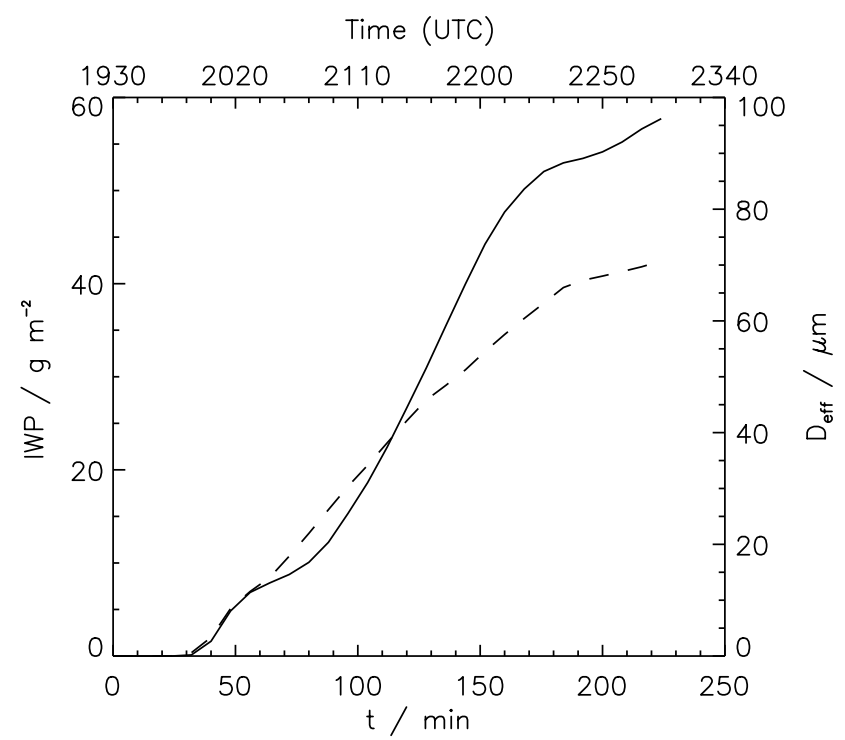

Figure 2. Evolution of mean cloud ice water path $\overline{\mathrm{IWP}}$ (solid curve) and cloud-mean effective diameter $\bar{D}_{\text {eff }}$ (dashed) for the EULAG-LCM results of the baseline case-study investigated in the present work. The associated short wave cloud mean optical depth, discussed later, is shown in Figure 12.

theory, and the measurements. Section 8 summarises the main points and concludes this paper by offering recommendations for future work.

\section{The DLR EULAG-LCM model system}

The EULAG-LCM is a large-eddy model designed to study cirrus clouds with a thorough, explicit representation of sizeresolved, non-equilibrium aerosol and ice microphysical processes. The dynamical core of our model is the anelastic, non-hydrostatic fluid model EULAG (Grabowski and Smolarkiewicz, 2002), to which we coupled a $1 \mathrm{D}$ radiative transfer scheme ( $\mathrm{Fu}, 1996)$. A combined Eulerian/Lagrangian approach is used to simulate the formation and evolution of cirrus clouds with the help of the new microphysical module LCM. Water vapour, trace gases, and size-resolved aerosol particles are treated over a fixed Eulerian grid similar to the dynamical and thermodynamical variables. By contrast, the ice phase is treated by Lagrangian tracking of a large number of SIPs in the turbulent flow field. Each SIP represents a number of real ice crystals with identical properties (SK10). The macroscopic properties of the ice phase (for instance, the ice water content or the cloud-induced radiative flux changes) are deduced from statistically analysing the properties of SIPs present in each model grid box.

The LCM covers non-equilibrium dissolutional growth and evaporation of water in liquid supercooled aerosol particles, their homogeneous freezing, heterogeneous nucleation of ice by solid ice nuclei (IN) in the deposition or immersion mode, depositional growth and sublimation of ice crystals by interaction with water vapour, their gravitational sedimentation, aggregation between ice crystals due to differential sedimentation, changes of ice crystal habits during growth, the effect of turbulent dispersion on ice particle trajectories, cloud-induced diabatic latent and radiative heating or cooling, and radiative heating or cooling of ice crystal surfaces. This enables us to simulate and analyse feedbacks between dynamical, microphysical, and radiative processes characteristic for cirrus. We refer to SK10 for a full description of the combined EULAG-LCM model system. 
(a)

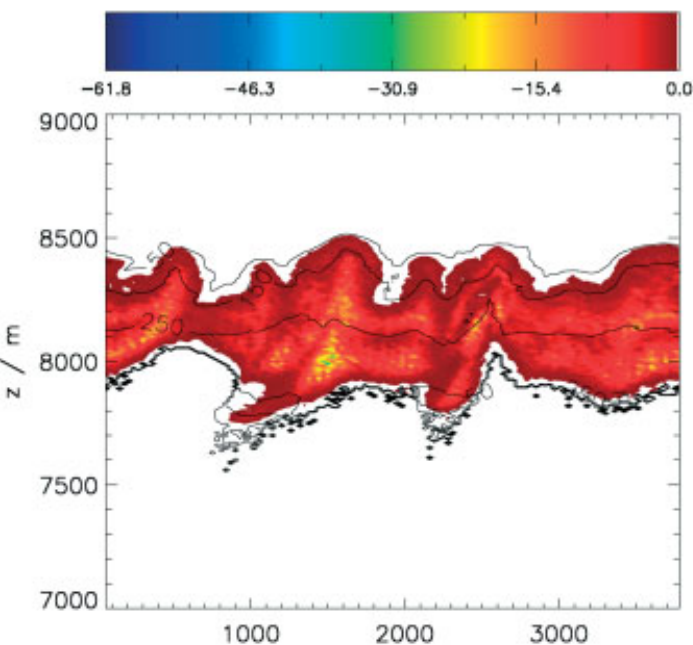

(c)

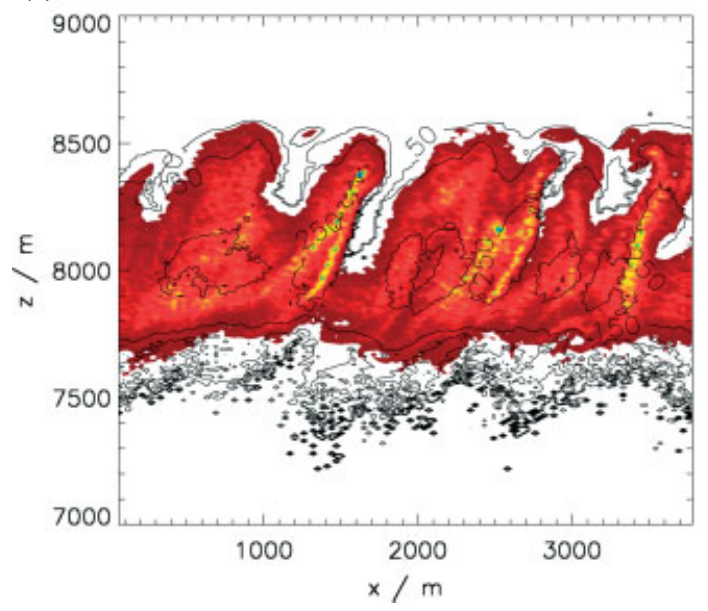

(b)
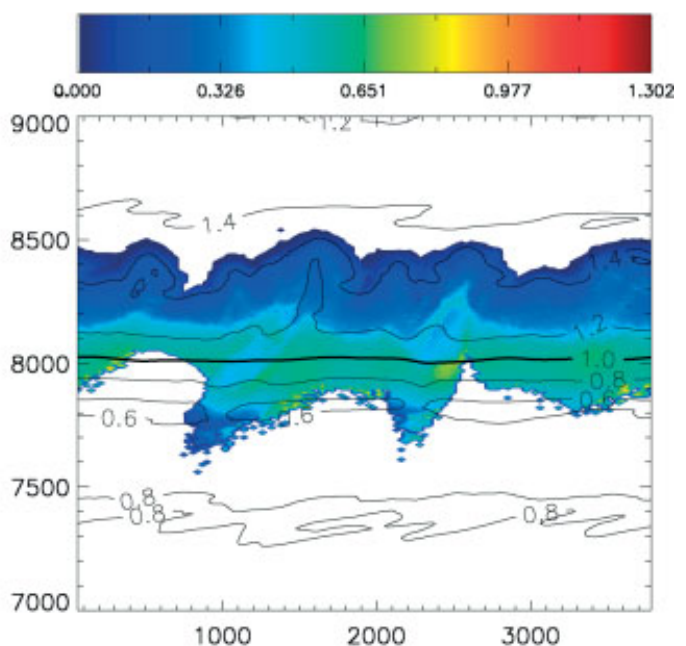

(d)

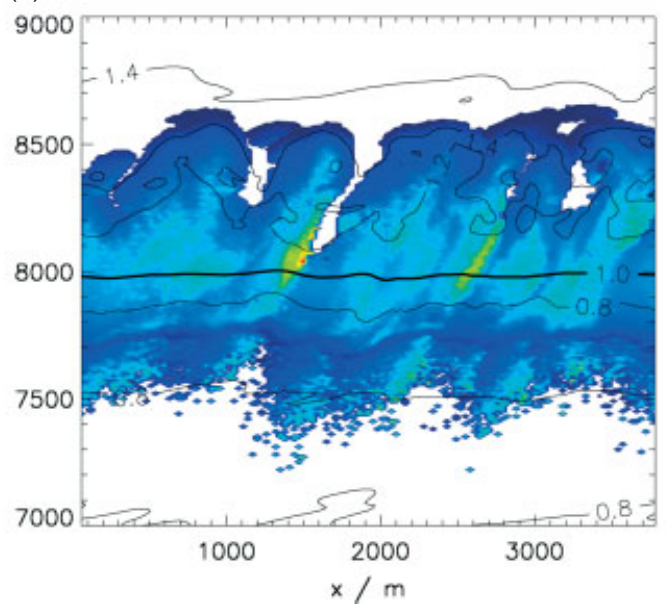

Figure 3. Two-dimensional distribution of (a) ice water mass flux (colour shading) and contours of the mean maximum dimension (at intervals of $100 \mu \mathrm{m}$, starting at $50 \mu \mathrm{m}$ ) and (b) terminal fall speeds (colour shading) averaged over all ice particles present in a grid box and contours of the ice saturation ratio (at intervals of 0.2 ). These are from EULAG-LCM results for the present case-study at about 50 min after formation (2020 UTC). (c, d) are as $(\mathrm{a}, \mathrm{b})$, but after $\sim 66 \mathrm{~min}$ (2036 UTC). These results highlight the small-scale variability in the cirrus cloud.

The evolution of ice PSDs in deep cirrus clouds is controlled in part by aggregation. Aggregation occurs when ice crystals in a cloud collide and eventually stick together, forming crystals of larger sizes and more complex habits. This type of aggregation in stratiform cirrus is mainly controlled by differential sedimentation (Westbrook et al., 2004; SK10). In the EULAG-LCM, aggregation by differential sedimentation is directly simulated on the basis of individual ice particle trajectories. The basic idea is that faster sedimenting ice crystals may overtake slower ones and both may form an aggregate crystal during a collision in proportion to the aggregation efficiency, $E_{\mathrm{a}}$. Our particlebased algorithm accounts for the resolved and subgrid scale vertical wind and sedimentation velocities attributed to the individual SIPs. For any pair of SIPs present in a model grid box, we check their vertical positions and forward trajectories for possible collisions. If a pair collides during a model time step, we evaluate the overall probability for aggregation to occur and create new, aggregated ice particles. We have validated this algorithm by means of an idealised simulation that reproduced the conditions in which the size distribution of aggregated ice crystals can be predicted by an analytical self-similar scaling relation (SK10). We will continue the validation of the entire model system in the present study by confronting the EULAG-LCM with a real cirrus cloud case.

Tracking ice particles and calculating the ice crystal size distribution directly in the EULAG-LCM increases confidence in simulating ice nucleation, sedimentation and aggregation, which need to be heavily parametrized in bulk microphysical schemes. Many of the data analyses presented in this study (e.g. in section 6) could not be carried out using bulk schemes. Explicit information on the habits across the ice crystal size distribution provided by our model potentially improves the calculation of cloud radiative forcing.

\section{Observational basis: The ARM IOP case-study - 9 March 2000}

\subsection{General description}

During the cloud IOP of the ARM project in spring 2000, the 3D structure and microphysical properties of midlatitude cirrus clouds were observed. We focus on the cirrus cloud field that formed in a weak upper-level disturbance on 9 March in a strong southwesterly flow (Comstock et al., 2007). After cloud formation during local morning (1400 UTC) 


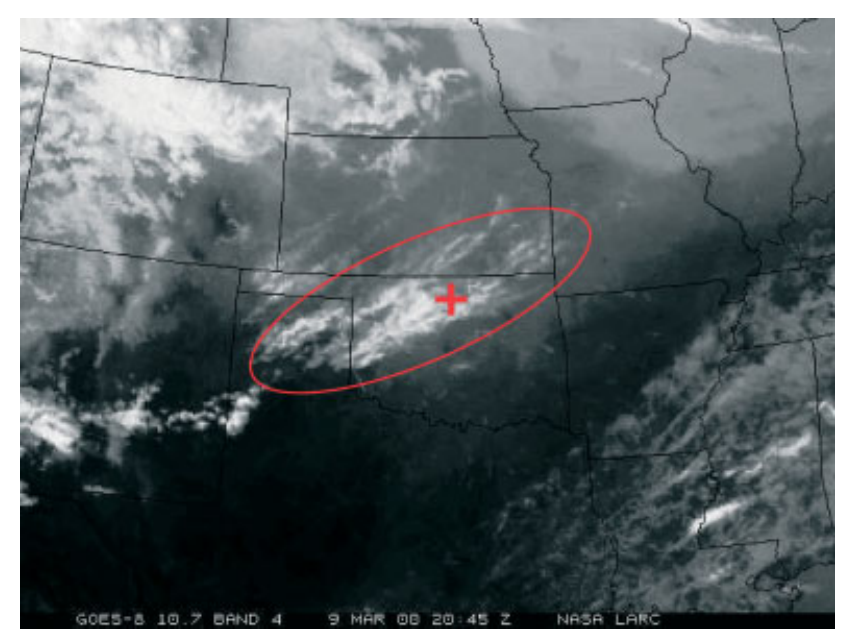

Figure 4. Geostationary satellite (GOES-8) infrared image of the cirrus field (moving from southwest to northeast) at 2045 UTC above Oklahoma, USA, on 9 March 2000. The red plus symbol indicates the location of the ARM Central Facility (CF) site. The red ellipse marks the entire cloud system studied here. The thin cirrus precursors of the main cloud are located northeast of the CF site and were formed earlier (around 1400 UTC) southwest of the CF site.

southwest of the CF site, the cloud evolved into bands oriented parallel to the main flow direction (southwest to northeast) and grew optically thicker while moving over the CF site (Figure 4). Further observations (aircraft in situ MPL, scanning MMCR, and radiosonde) were peformed at the CF site.

The MPL and MMCR measurements identifed a thick cirrus layer at later stages (cloud base at $6 \mathrm{~km}(\sim 450 \mathrm{hPa})$, cloud tops near $10 \mathrm{~km}(\sim 250 \mathrm{hPa})$ above the CF site between 2100 and 2200 UTC (Comstock et al., 2007). Occasionally, the MPL detected optically thin clouds above the actual main cloud layer. No underlying warm clouds were detected on that day. Different retrival algorithms (based on lidar, radar, Doppler velocity, or infrared radiometer data) estimated optical depths in the range 2-3 at wavelengths in the visible (solar) region (Comstock et al., 2007) over the CF site at 2145 UTC. Photographs from a ground-based camera, displaying the whole sky above the CF site, reveal a considerable inhomogeneity of the cloud field, consistent with Figure 4.

\subsection{Data sources}

Radiosondes were launched every $3 \mathrm{~h}$ at the CF and four surrounding sites. The moisture radiosonde data were corrected for known biases of the sensors (temperature-dependence, contamination, time-lag corrections) according to Miloshevich et al. (2001). We show the ice saturation ratio profiles, $S_{\mathrm{i}}(z)$, for several radiosonde ascents between 1730 and 2330 UTC in Figure 5(a). The moist layer between 350 and $300 \mathrm{hPa}$ (corresponding to $\sim 8.5 \mathrm{~km}$ and $10 \mathrm{~km}$ altitude) at 1730 UTC was measured in cloud-free air according to the MMCR reflectivites, although it cannot be ruled out that few small ice crystals were present. The peak ice saturation ratio is $S_{\mathrm{i}} \approx 1.4$. Below $350 \mathrm{hPa}, S_{\mathrm{i}}$ decreases and the air is subsaturated. At later times, the subsaturated layer is hydrated considerably (down to $400 \mathrm{hPa}$ at $2030 \mathrm{UTC}$ and $450 \mathrm{hPa}$ at 2330 UTC), while the supersaturation in the moist layer is substantially reduced. Reanalysis data of the equivalent potential temperature field do not point at horizontal advection of moist air masses. It is therefore conceivable that the evolution of the moisture profiles can be mainly attributed to cloud processes and vertical air motion.

The radiosonde temperature profiles show that the atmosphere between 500 and $250 \mathrm{hPa}$ was stably stratified, with an average squared Brunt-Väisälä frequency of $N^{2}=0.625 \times 10^{-5} \mathrm{~s}^{-2}$. Inspection of aircraft data from horizontal flight legs indicates the presence of small-scale velocity and temperature fluctuations, very likely attributed to gravity waves caused by the flow crossing the nearby Rocky Mountains (Huiyi Yang, personal communication, 2009). Assuming a stationary wave field $(\partial T / \partial t=0)$, we obtain a rough estimate for the corresponding updraught velocities, $w_{\text {grav }}$, via:

$$
\frac{\mathrm{d} T}{\mathrm{~d} t}=u \frac{\partial T}{\partial x} \Longrightarrow-w_{\text {grav }} \frac{g}{c_{p}} \simeq u \frac{\delta T}{\lambda} .
$$

(Symbols are defined in Appendix B.) From the aircraft data, we estimate an average horizontal wind speed $u=20 \mathrm{~m} \mathrm{~s}^{-1}$ parallel to the flow direction and $\partial T / \partial x \simeq$ $0.01 \mathrm{~K} \mathrm{~km}^{-1}$. This temperature gradient represents waveinduced, mesoscale fluctuations, whose amplitudes and typical wavelengths we have estimated to be $\delta T \simeq 0.1 \mathrm{~K}$ and $\lambda \simeq 10 \mathrm{~km}$, respectively. Taken together, this leads to $\left|w_{\text {grav }}\right| \simeq 0.02 \mathrm{~m} \mathrm{~s}^{-1}$.

Updraught speeds were derived by Zhang et al. (2001) based on the constrained variational analysis method, using sounding data of the boundary facilities around the CF site. This analysis may not capture the full range of variability in vertical air motions. The magnitude of the vertical wind speeds on the scale of the cloud may be underestimated and their temporal evolution as a function of altitude may not fully represent the actual meteorological situation. Nevertheless, these estimates are a useful guide to drive the model. They suggest a rather weak uplift initially (1730 UTC), peaking at $w=0.03 \mathrm{~m} \mathrm{~s}^{-1}$, which increases to $0.08 \mathrm{~m} \mathrm{~s}^{-1}$ until 2330 UTC (Figure 6). Updraught speeds are largest in the middle troposphere at $500 \mathrm{hPa}(\sim 5500 \mathrm{~m})$ but this may be biased by the constraints in the analysis method (Zhang et al., 2001). Because of these uncertainties, we apply a constant, average updraught speed $w_{0}=0.055 \mathrm{~m} \mathrm{~s}^{-1}$.

Microphysical and meteorological in situ data were taken on board the University of North Dakota Citation aircraft that performed numerous flight patterns in the cloud above the CF site between 1830 and 2230 UTC. Cloud microphysical properties where probed with a CVI, to determine the IWC with a lower detection limit of $3 \mathrm{mg} \mathrm{m}^{-3}$, a CPI to study the habits of ice crystals with a resolution of $2.3 \mu \mathrm{m}$, and optical particle probes (2D-C and 2D-P) to measure ice PSDs. The $2 \mathrm{D}$ probes classified ice crystals with sizes between $33 \mu \mathrm{m}$ and $1000 \mu \mathrm{m}$, and $200 \mu \mathrm{m}$ and $6000 \mu \mathrm{m}$, respectively (Heymsfield et al., 2002). Presumably, these instruments detected all ice crystals. In nature, ice crystals with sizes below the lowest size cut-off grow very quickly and, if present, should therefore constitute only a small portion of the total concentration.

Difficulties in measuring the number concentration of small ice particles due to particle shattering and optical focusing have been discussed in the literature (Lawson et al., 2006; Field et al., 2006; Heymsfield, 2007; Jensen et al., 2009). The imaging probes are believed to measure PSDs reliably above $\sim 125 \mu \mathrm{m}$ (Heymsfield et al., 2008). In the 
presence of larger aggregated ice crystals in the dataset, the abundance of small $(<50-100 \mu \mathrm{m})$ ice crystals may be overestimated. A reanalysis of the ARM 2DC data to remove shattering using the interarrival time method (Field et al., 2006) indicated that shattering was minimal for this case (Andrew Heymsfield, personal communication, 2010).

A Lagrangian spiral descent flight pattern (Lo and Passarelli, 1982) was conducted with the probing aircraft between 2130 and 2225 UTC in the cloud system over the CF site. While flying narrow spirals and drifting with the horizontal wind, the aircraft descended with an estimated average velocity of the sedimenting ice crystal population, $\sim 1 \mathrm{~m} \mathrm{~s}^{-1}$. The aircraft entered the cirrus layer from above at 2130 UTC southwest of the CF site and drifted northeastwards. The downward spiral right above the CF site was conducted around 2145 UTC. Field and Heymsfield (2003) analysed the measured IWC fields from successive spirals and ascertained that the aircraft, while heading between $140^{\circ}$ and $300^{\circ}$, mostly probed the same cloud region.

We mimic the horizontally drifting, spiral descent pattern when sampling air and cirrus properties in our model to enable the closest possible comparison with the in situ data (section 5). Specifically, we analyse individual spirals in the measurements over a distance of $15 \mathrm{~km}$ and $280 \mathrm{~m}$ in the flight and vertical directions, respectively. This sampling pattern allows us to follow roughly the same population of sedimenting and aggregating ice crystals in the cloud at the times of the observations.

\section{Simulation set-up}

We simulated cirrus cloud formation and evolution in a $2 \mathrm{D}$ cross-section, initially located upstream of the $\mathrm{CF}$ site and oriented parallel to the prevailing horizontal wind direction. Periodic lateral boundary conditions were applied. We follow the domain as it is advected across the $\mathrm{CF}$ site with the mean flow. We summarise several parameter settings for our standard (baseline) simulation in Table I. Aircraft data (spiral descent) are available for $\sim 60 \mathrm{~min}$. To cover the observation period (including the cloud formation phase) and study the subsequent evolution of the cloud system, we ran the simulations for a longer time period, chosen to be $224 \mathrm{~min}$.

Based on the observations, it is not possible to determine the exact moment and location when the individual cirrus segments, probed at the CF site, formed. Hence, there is no unique solution for the initialisation of the simulations. However, the data sources (section 3.2) constrain some key initial profiles. Furthermore, we make plausible assumptions regarding possible ice nucleation pathways, for which the observations do not provide any direct clues.

\subsection{Initial atmospheric vertical profiles}

We apply a Galilean transformation to the entire simulation domain, i.e. we move our coordinate system upwards according to the prescribed vertical velocity $w_{0}$ (section 3.2). Environmental background profiles of temperature and pressure are modified according to the adiabatic lapse rate. Using constant environmental potential temperature, $\theta_{e}$, for the cloud-free background profile, the associated adiabatic
Table I. ARM IOP 9 March 2000 simulation settings for the base run. Initial vertical profiles of ice saturation ratio, potential temperature, and updraught speed are discussed in the text. The time between subsequent calls of the radiation routine is $40 \mathrm{~s}$.

\begin{tabular}{ll}
\hline Domain & \\
Grid cells & $128 \times 244$ \\
Grid spacing & $\Delta x=30 \mathrm{~m} ; \Delta z=20 \mathrm{~m}$ \\
Time steps & $\Delta t=4 \mathrm{~s} ; \Delta t_{\mathrm{M}}=2 \mathrm{~s} ; \Delta t_{\mathrm{N}}=0.25 \mathrm{~s}$ \\
Start time & $1930 \mathrm{UTC}$ \\
Total run time & $224 \mathrm{~min}$ \\
Stability & $N^{2}=6.25 \times 10^{-5} \mathrm{~s}^{-2}$ \\
Wind shear & $\partial u / \partial z=1 \times 10^{-3} \mathrm{~s}^{-1}$ \\
Updraught speed & $w_{0}=5.5 \mathrm{~cm} \mathrm{~s}^{-1}$ \\
Ice properties & \\
Deposition coefficient & $\alpha_{v}=0.5$ \\
Habit & $30 \%$ pristine ice, hexagonal columns \\
& (variable aspect ratios); \\
& $70 \%$ bullet rosettes. \\
Aggregation & Variable fraction of aggregates. \\
$N_{\text {SIP }}$ & $E_{\mathrm{a}}=0.75$ \\
Aerosol & $12.7 \times 10^{6}$ \\
Type & \\
Ice nucleation & Aqueous sulphuric acid droplets. \\
$\quad$ Radiation & Homogeneous freezing. \\
Background & Standard profiles for: \\
& $\mathrm{O}_{3}, \mathrm{CO} \mathrm{O}_{2}, \mathrm{O}_{2}, \mathrm{CH} \mathrm{H}_{4}, \mathrm{~N}_{2} \mathrm{O}$. \\
Simulated & EULAG-LCM profiles for: \\
& $\mathrm{H}_{2} \mathrm{O}, T, p, D_{\mathrm{ge}}, \mathrm{IWC}$. \\
Particles & No radiative effects on \\
& ice crystal growth. \\
\hline &
\end{tabular}

cooling rate follows from

$$
\frac{\mathrm{d} T_{e}}{\mathrm{~d} t}=\frac{\mathrm{d} T_{e}}{\mathrm{~d} z} \frac{\mathrm{d} z}{\mathrm{~d} t}=-\frac{g w_{0}}{c_{p}} .
$$

Air pressure and density are then modified with the help of the adiabatic equation of state.

In Figure 5, we display the EULAG-LCM inital profiles and radiosonde profiles of $S_{\mathrm{i}}$ and $\theta$ versus air pressure at various times of cloud evolution.

We reproduce the static stability of the probed atmospheric layer, but use a smoothed initial $\theta$ profile to avoid numerical instabilities. The $S_{\mathrm{i}}$ profile at 1730 UTC (dotted curve) likely represents cloud-free air. The profile at 2030 UTC may have already been modified by cloud processes (since, by then, cloud ice particles could have redistributed water in the vertical column). We relate the initial EULAG-LCM $S_{\mathrm{i}}$ profile to the early (1730 UTC) radiosonde profile. This is supported by the fact that the air mass did not change due to horizontal advection before the cloud formed (section 3.2). The inital profile is shifted downward as the layer ascends during advection towards the CF site.

The subgrid scale turbulence closure from EULAG (SK10) was used in all of our simulations. We superimpose a grid scale ambient turbulence field (mean eddy dissipation rate of $\epsilon=3 \times 10^{-6} \mathrm{~m}^{2} \mathrm{~s}^{-3}$ and corresponding temperature 

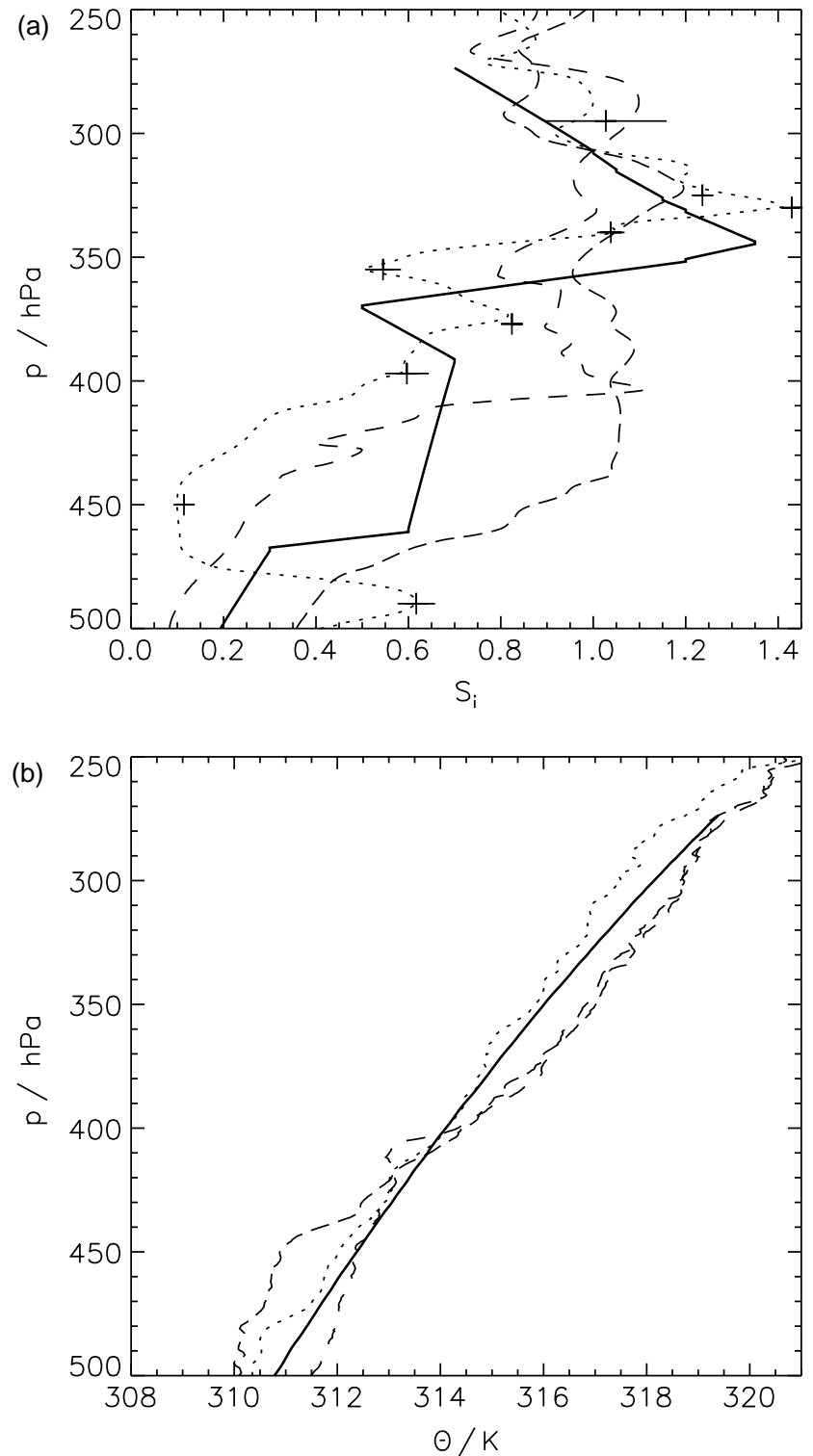

Figure 5. Radiosonde profiles of (a) ice saturation ratio, $S_{\mathrm{i}}$, and (b) potential temperature, $\theta$, at the CF site from the ascents at $1730 \mathrm{UTC}$ (dotted), 2030 UTC (long dashed), and 2330 UTC (dashed). For the measurement at 1730 UTC, the average absolute error and its standard deviation for $S_{\mathrm{i}}$ are also shown (pluses) according to Miloshevich et al. (2006). The solid curves in both panels show the initial profiles prepared for the EULAG-LCM simulations.

fluctuations $\delta T=0.02 \mathrm{~K}$ in clear air) onto the model domain, which we generated with separate $3 \mathrm{D}$ EULAG simulations. We note that typical in-cloud values of $\epsilon$ range between $10^{-5}$ and $10^{-4} \mathrm{~m}^{2} \mathrm{~s}^{-3}$ according to our simulations.

\subsection{Freezing aerosol properties and ice crystal growth}

The concentration and chemical composition of background aerosols have not been measured during the campaign. Liquid droplets, composed of aqueous supercooled sulphuric acid $\left(\mathrm{H}_{2} \mathrm{SO}_{4}\right)$ solutions, serve as homogeneous freezing nuclei in the model. Ten size classes are introduced to model the liquid aerosol population, assuming a spatially homogeneous initial lognormal distribution with total number concentration $100 \mathrm{~cm}^{-3}$, geometric mean diameter $0.1 \mu \mathrm{m}$, and geometric standard deviation 1.5 for the dry $\mathrm{H}_{2} \mathrm{SO}_{4}$ droplets. The simulation results are not very sensitive to this choice (Kärcher and Lohmann, 2002). The dry aerosol particles are equilibrated with the ambient water vapour in the first time step, while their size-dependent binary composition changes in the course of the simulations due to water vapour uptake (dissolution) and evaporation. The water activity in each droplet together with the droplet volume then determine the homogeneous freezing rate, hence, the number of new ice particles generated and tracked in the model (SK10).

Given the ubiquity of homogeneous freezing in the atmosphere (Cziczo et al., 2004; Kärcher and Spichtinger, 2009) and the fact that its activity-based formulation (Koop et al., 2000) is well established (Richardson et al., 2010) over the temperature range $(215-240 \mathrm{~K})$ considered in the present study, we assume homogeneous freezing of the liquid aerosol droplets to be the sole ice nucleation pathway in the baseline simulation. The measured high saturation ratios of $S_{i} \simeq 1.4$ (Figure 5 ) lie already very close to the homogeneous freezing threshold, justifying this option. We neglect the potential impact of additional heterogeneous IN in the baseline simulation, but consider IN as a perturbation to the base case in section 7 . 


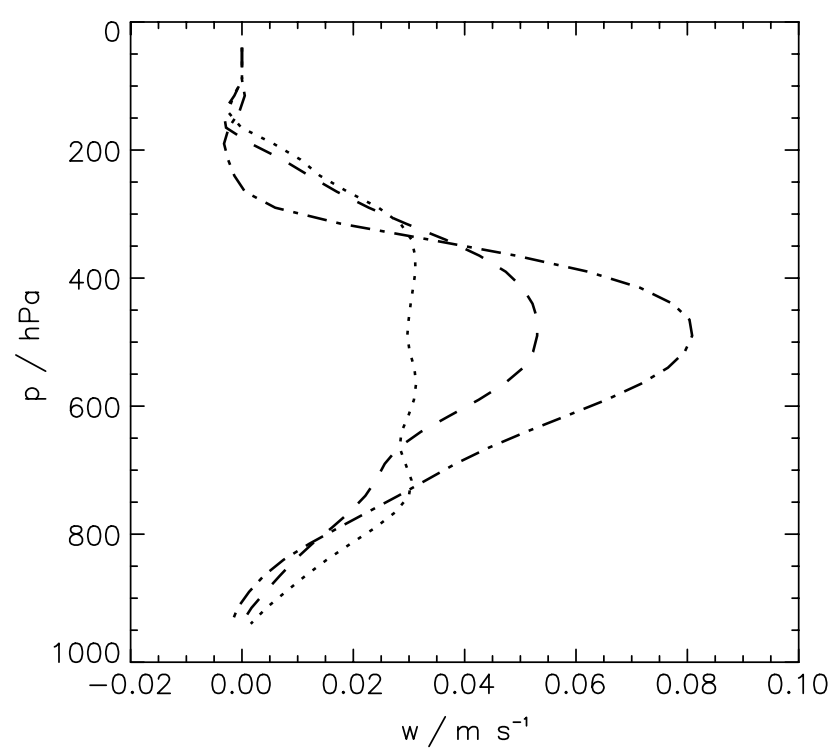

Figure 6. Updraught speed $w$ after Zhang et al. (2001) at 1730 UTC (dotted), 2030 UTC (dashed), and 2330 UTC (dash-dotted). We use $w=w_{0}=0.055 \mathrm{~ms}^{-1}$ to initialise and perform the EULAG-LCM simulations at 1930 UTC (see text).

All ice crystals, including aggregates, grow by uptake of water vapour from the gas phase (depositional growth). The growth rate has been corrected for gas kinetic effects, ice particle shape (Section 4.3) and ventilation. This growth mechanism becomes inefficient in the size range above about $500 \mu \mathrm{m}$, see Figure 13. The depositional growth rate depends on a shape factor that has been taken from the detailed study of Westbrook et al. (2008), which is consistent with the present observations. This shape factor may modify the growth rate of crystals by up to $30 \%$ (e.g. between aggregates and columns).

As input to the radiation module (Table I), we employ midlatitude winter standard profiles from Anderson et al. (1986), slightly modified at the ground level to fit the local meteorological soundings. The solar zenith angle varies with the local time. The resulting clear air solar flux computed at the surface at 1700 UTC (local noon) is $842 \mathrm{~W} \mathrm{~m}^{-2}$, in agreement with the observations of Comstock et al. (2007).

\subsection{Ice crystal habits}

The EULAG-LCM simulates a combination of different ice particles habits at any time (SK10). In our model, ice particle habits influence depositional growth rates and terminal fall speeds, hence they affect the evolution of the ice crystal PSDs. We make use of the CPI images to constrain the simulated evolution of ice crystal habits. According to Heymsfield et al. (2002), the probed cirrus was composed mainly of single bullet rosettes and aggregates of bullet rosettes. Further inspection revealed some ice particles with either columnar shape, or a more compact (possibly still columnar) shape for small crystals with aspect ratios near unity.

To account for the observed ice particle habits, we model a mixture of habits tailored to this specific observation. In the baseline simulation, we attribute a probability of $30 \%$ that the freshly nucleated ice particles evolve as hexagonal columns with variable aspect ratios and that $70 \%$ grow into bullet rosettes, broadly consistent with the in situ data. If ice crystals aggregate, we transfer them to the third (aggregated) shape category. The smallest particles have aspect ratios starting at unity and grow more rapidly along their c-axes with increasing mass (which increases the aspect ratio). SK10 compiled the mass- and area-dimensional relationships for the present case following Mitchell (1996) and Heymsfield et al. (2002).

\section{Simulation results}

The drifting spiral descent flight pattern of the probing aircraft (section 3.2) allows us to generate vertical profiles of the evolving cirrus field for comparison with the observations. The time span between the aeroplane's first encounter with the cloud and its last spiral at cloud bottom was nearly $1 \mathrm{~h}$. We mimic spiral descents through the simulated cirrus as follows. We take averages of cloud properties over individual spirals in the simulated cirrus at subsequent sampling time intervals $(\Delta \mathcal{T}=8 \mathrm{~min})$. We start near the cloud top at a height $H_{1}=9600 \mathrm{~m}$ (vertical centre of the top layer) at $t=\mathcal{T}_{1}=136 \mathrm{~min}$ and average our results over the total horizontal cloud region to capture the full horizontal variability of the 2D simulations. These results are representative for several vertical layers with heights separated by $\Delta H=\bar{v}_{\mathrm{t}} \Delta \mathcal{T}=480 \mathrm{~m}$ in the simulation domain. Here, $\bar{v}_{\mathrm{t}}=1 \mathrm{~m} \mathrm{~s}^{-1}$ is an average sedimentation velocity of the ice particle population (Field and Heymsfield, 2003). The subsequent spirals and our averaged cloud properties are associated with the layer centres $H_{k+1}=H_{1}-k \cdot \Delta H$ (integer $\left.k \geq 0\right)$.

The red diamonds in Figure 7 are the resulting average values, with the horizontal bars indicating the minimum and maximum values in each simulated spiral. Figure 7 compares our simulation results $\left(n_{\mathrm{i}}, D_{1}, S_{\mathrm{i}}\right.$, and $\left.\theta\right)$ with the in situ measurements.

Considering $n_{\mathrm{i}}$, the simulated and measured values agree very well in terms of magnitude and vertical distribution. The variability of the simulated maximum and minimum values lies mostly within the measured range.

The simulated vertical profile of $S_{\mathrm{i}}$ closely resembles that from the radiosonde observations. We simulate the dry layer below $420 \mathrm{hPa}$ and the supersaturated region at cloud top fairly well. Furthermore, our model captures the reduction and homogenisation of $S_{\mathrm{i}}$ in the initially supersaturated cloudy regions between 420 and $320 \mathrm{hPa}$. However, $S_{\mathrm{i}}$ values in the cloud are slightly higher in the model than in the measurements but differences in $S_{\mathrm{i}}$ of $\sim 0.1-0.2$ may well lie within the uncertainties of the relative humidity measurements. Aircraft and radiosonde relative humidity data are similar at 2030 UTC.

The potential temperature, $\theta$, is modelled reasonably well. Latent heat release and consumption during growth and sublimation of the ice crystals, respectively, alters the initially constant static stability in the model. Radiative effects are less important in our case. Latent heat is consumed in the lower cloud regions, where ice crystals sublimate. At the cloud top $(<310 \mathrm{hPa})$, latent heating reduces the static stability. Between 400 and $430 \mathrm{hPa}, \partial \theta / \partial z$ increases (the stability increases) but for $p>430 \mathrm{hPa}, \partial \theta / \partial z$ decreases (the stability decreases). We are not able to simulate the observed shift from higher to lower stability in the middle of the cloud (around $370 \mathrm{hPa}$ ). We point out that it may not be possible to attribute changes in the $\theta$ profile to cloud processes alone, because the $2 \mathrm{D}$ approach does not resolve the complex dynamical lifting associated with the actual flow field in the entrance and exit region of the southwesterly 

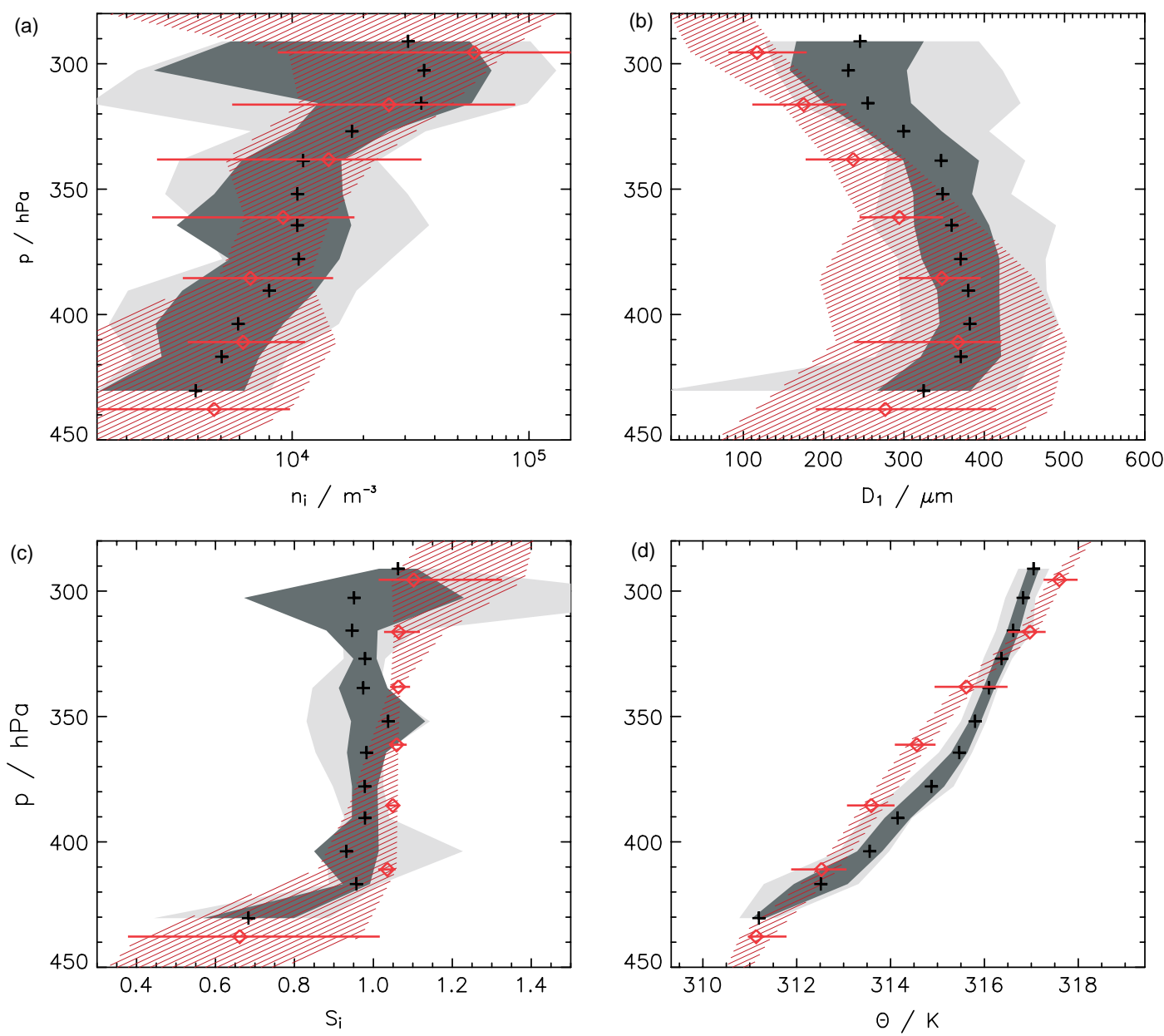

Figure 7. Measured (black pluses) and simulated (red diamonds) baseline values of (a) grid box average total (all sizes) ice crystal number density $n_{\mathrm{i}}$, (b) number-weighted mean maximum ice crystal dimension $D_{1}$, (c) ice saturation ratio $S_{\mathrm{i}}$, and (d) potential temperature $\theta$ sampled between 2130 and 2225 UTC along spirals extending vertically downward into the cloud (see text). The dark grey areas denote the $\pm \sigma$ interval (one standard deviation) and the light grey area the minimum to maximum range of the measured values. Min-max ranges from the simulations (red horizontal bars) are also included, and the red-shaded regions represent the ranges of mean values obtained from 27 sensitivity runs (section 7 ).

jet, which may explain part of the differences between the observed and simulated $\theta$ profiles.

A pronounced difference between simulation results and measurements is the lack of large crystals in the upper part $(300-380 \mathrm{hPa})$ of the simulated cirrus (ice crystals with number-weighted maximum dimension $D_{1}>100-200 \mu \mathrm{m}$ in Figure 7, or with maximum dimensions of individual ice crystals, $D>1500-2000 \mu \mathrm{m}$, as shown in Figure 8). Such large ice particles are also evident in the CPI images, showing that ice particles there consist of a mixture of bullet rosettes and aggregates thereof.

We offer three mechanisms to explain the missing large ice crystals in the upper cloud region in the model. First, they may have originated from an optically thin cirrus cloud layer located above the probed cloud system. Ice crystals from aloft could have reached the underlying cirrus by sedimentation. Overlying clouds are not considered in our simulation setup. This very plausible hypothesis is supported by the MPL data, showing backscatter signals above the simulated cloud over the CF site (section 3).

Second, ice crystals may have been lifted in small updraught regions present in the cloud. Heymsfield et al. (2002) report embedded cells and trails (cirrus uncinus) in the cirrus cloud field on 9 March 2000. However, to keep the large ice crystals at a given height, a vertical wind speed of $\sim 0.8 \mathrm{~m} \mathrm{~s}^{-1}$ is required to balance their terminal fall speeds, or even larger to actually lift them. In our model, peak vertical velocities are $\sim 0.35 \mathrm{~m} \mathrm{~s}^{-1}$ in the upper cloud regions, too small to transport such large crystals upwards, but we cannot rule out this possibility.

Third, aggregation could have been more effective in the upper part of the cloud than simulated. However, we already used a rather high aggregation efficiency of 0.75 in the base case. Turbulent mixing in unresolved convective cells could enhance the rate of aggregation, a mechanism not included in our model. For the simulated cloud case, however, peak in-cloud eddy dissipation rates are $10^{-4} \mathrm{~m}^{2} \mathrm{~s}^{-3}$, too small to render turbulent aggregation more important than aggregation by differential sedimentation (SK10). Moreover, the CPI images also indicate the presence of large but nonaggregated bullet rosettes in the upper cloud. The growth of such particles cannot be explained by aggregation. In the lower part of the cirrus, the simulated, number-weighted mean maximum dimensions agree with the measured values. The observed slope of the exponential tail of the PSDs at large sizes is well reproduced in the simulation, as is the change from an exponential to a superexponential shape towards smaller crystals $(D<500 \mu \mathrm{m})$. At these smaller sizes, the impact of depositional growth is important, and we predict the observed reduction of the mean ice particle maximum dimension in the dry sublimation layer at cloud 

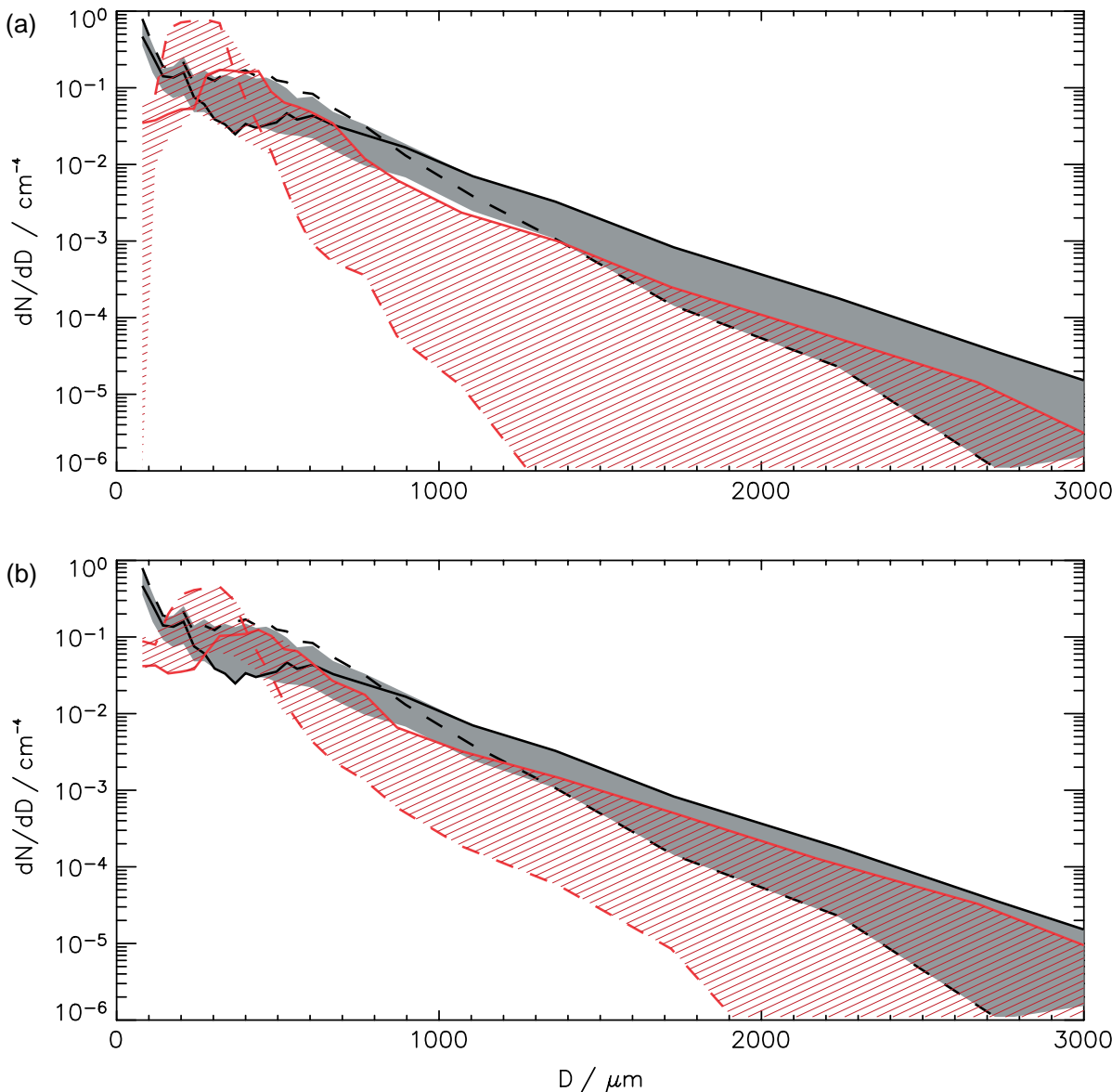

Figure 8. Measured (grey) and simulated (red) ice particle size distributions for subsequent spirals (a) during the descent through the cloud deck from the base case and (b) from the sensitivity run J (section 7). The dashed curves correspond to PSDs from the spiral at a mid-cloud level $(p=360 \mathrm{hPa}$ ) at $168 \mathrm{~min}$. The solid curves are PSDs from near the cloud base but above the sublimation zone at $420 \mathrm{hPa}$ and $174 \mathrm{~min}$. Shaded and hatched areas represent ensembles of many PSDs which are not plotted individually but taken at different times during the sampling in the model (equivalent to the aircraft sampling in the spiral descent flight pattern). In Figure 7 we show the corresponding vertical distributions of cloud parameters.

bottom. Taken together, the PSDs in the lower parts of the spirals are well simulated.

Therefore, we conjecture that the disagreement between model and observations concerning the presence of large ice crystals at the cloud top is likely caused by a thin cirrus above the probed cirrus cloud system. However, the presence of a small number of IN particles in the upper region of the simulated cloud would possibly have a similar effect. By contrast, IN present in lower levels of the cloud would have only little impact on our results, because the ice crystals forming on them would very quickly fall out of the cloud. Due to additional uncertainties in specifying the vertical profiles of updraught and initial supersaturation, it is not possible to reach a definite conclusion on this issue.

Another marked difference exists in the small size range (for $D<100-200 \mu \mathrm{m}$ ), where the simulation predicts fewer ice particles than observed (Figure 8), especially in the lower cloud region. On the one hand, the measurements are less reliable in this size range due to shattering of large ice particles, resulting in artificially enhanced small ice crystal concentrations. However, as discussed in section 3.2, shattering was judged to exert only a small effect on the observed size distributions. On the other hand, additional vertical air motion variability, not represented in our model, would lead to more rapid cooling rates. The resulting enhanced production of numerous small ice crystals by homogeneous freezing may help to explain these differences, especially in the upper cloud regions in the size range $D<50 \mu \mathrm{m}$, as would perhaps additional horizontal variability not captured in a $2 \mathrm{D}$ simulation set-up.

\section{Analysis of aggregation processes}

In the following, we elucidate the role of aggregation of ice crystals in the simulated cirrus cloud for the ARM IOP base case. As discussed in SK10, the model simulates aggregation caused by differential sedimentation. The microphysics of the sticking process and the hydrodynamics of the flow around the colliding crystals are parametrized in the aggregation efficiency $E_{\mathrm{a}}$, while the probability of collisions to occur between the ice crystals is explicitly simulated through Lagrangian tracking of SIPs (LPT). By tracking the histories of individual ice aggregates in the EULAG-LCM, we are able to address the questions: How and where do particles with sizes $D>2000 \mu \mathrm{m}$ form in deep, stratiform cirrus clouds? Can we identify the processes which make aggregation especially efficient?

\subsection{Origin of large ice crystal aggregates}

Figure 9 depicts the evolution of a large subset of SIPs (overlapping thin grey curves). We take advantage of the LPT approach and record the maximum ice crystal dimensions, $D$, the number of aggregation events, and the terminal fall 

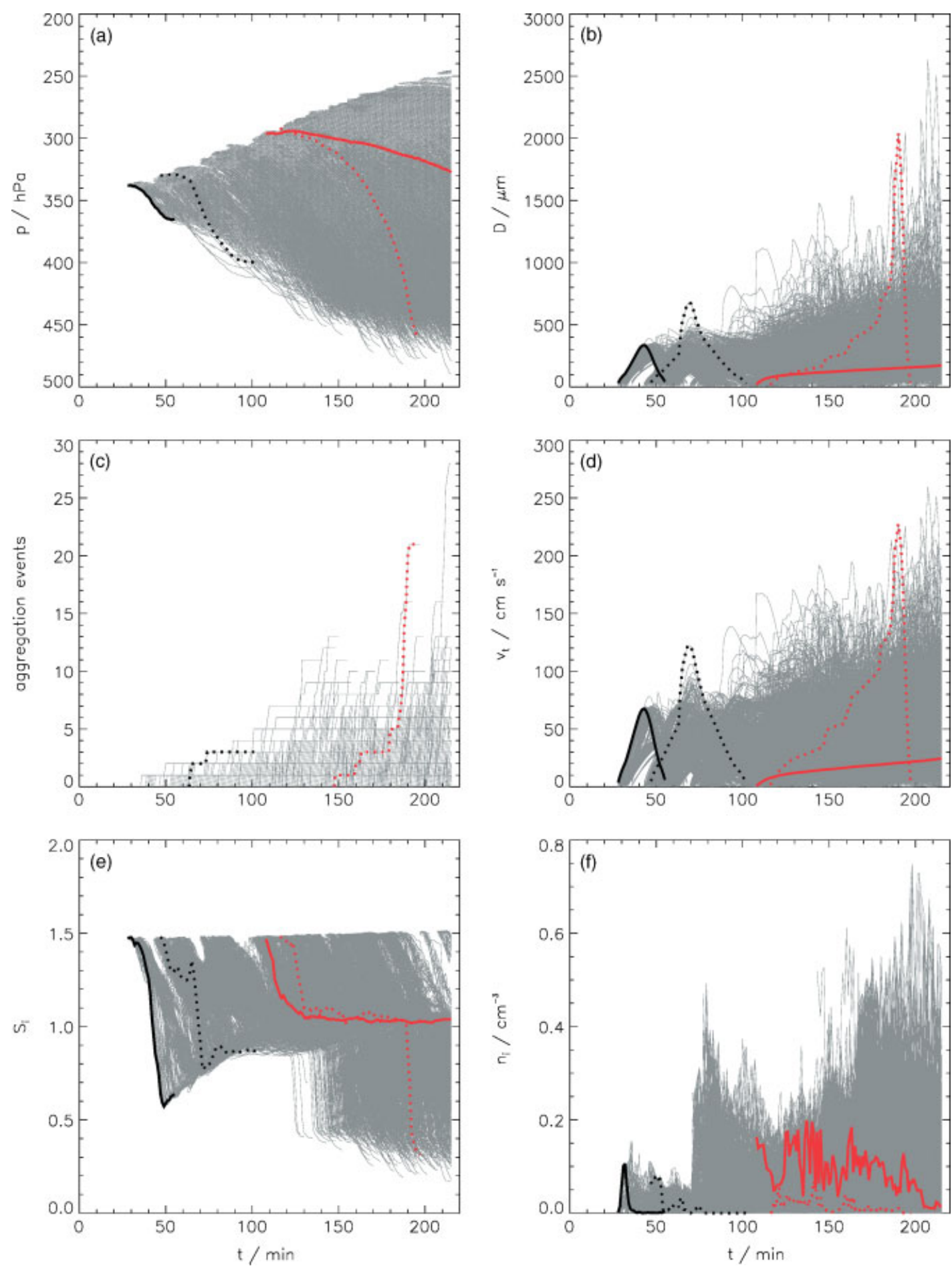

Figure 9. Temporal evolution of (a) air pressure $p$, (b) maximum dimension of ice crystals $D$, (c) number of aggregation events, (d) terminal settling velocity $v_{\mathrm{t}}$, (e) ice saturation ratio $S_{\mathrm{i}}$, and (f) number concentration $n_{\mathrm{i}}$ for a large number of individual simulation ice particles (ensemble of overlapping thin grey curves). The number of aggregation events, $D$, and $v_{\mathrm{t}}$ are associated with each SIP, while $p, S_{\mathrm{i}}$, and $n_{\mathrm{i}}$ refer to the grid point values in which the SIPs reside. Trajectories (black and red solid and dashed bold curves) of selected SIPs are discussed in the text.

speeds, $v_{\mathrm{t}}$, associated with these SIPs as a function of time, $t$. In addition, we show the air pressure, $p$, the ice saturation ratio, $S_{\mathrm{i}}$, and the ice crystal number density, $n_{\mathrm{i}}$, in the grid boxes containing the SIPs. The grey regions can be viewed as a measure of the variability in these parameters at any given time. We highlight the trajectories of two SIPs in the early stage of cloud evolution, labelled 1 (black solid curve) and 2 (black dotted), and of two SIPs in the mature stage of the cirrus, labelled 3 (red solid curve) and 4 (red dotted).
In the early stage $(t<50 \mathrm{~min})$, ice crystals nucleate in a narrow region, where the ice supersaturation reaches the high homogeneous freezing levels $\left(S_{\mathrm{i}} \simeq 1.5\right)$. SIP 1 is one of the first in the model to form (at $t=30 \mathrm{~min}$ ). Later on, it does not aggregate (number of aggregation events remains zero), because in that early stage, the ice crystals are size-sorted in the vertical and they sediment mainly through cloud-free air. The increase in size of SIP 1 is controlled by depositional growth until it reaches the subsaturated layer at $t \simeq 45 \mathrm{~min}$, where it begins to sublimate. SIP 1 
totally sublimates at $t=60 \mathrm{~min}$ and is removed from the simulation after releasing its aerosol core.

SIP 2 forms 20 min later at a higher altitude and grows more rapidly than SIP 1 in an environment with smaller ice crystal concentration. Later, it sediments in underlying cloud regions that are already populated with smaller ice particles that sediment more slowly. This enhances the aggregation probability; consequently, the number of aggregation events for SIP 2 increases to 3. Accordingly, the ice crystals represented by SIP 2 grow to larger peak sizes $(\sim 650 \mu \mathrm{m})$ than those in SIP $1(\sim 350 \mu \mathrm{m})$.

In the mature stage $(t>120 \mathrm{~min})$, the whole cirrus layer expands to $2.5-4 \mathrm{~km}$ depth. Due to adiabatic cooling imposed by the constant vertical wind speed, the cloud top still rises. Ice crystals continue to nucleate there in a strongly supersaturated layer. We now inspect the temporal evolution of SIP 3 and SIP 4. Both SIPs nucleate approximately in the same region at $300 \mathrm{hPa}$, but they evolve very differently.

SIP 4 sediments through the entire cloud and forms very large ice crystal aggregates (the maximum dimension reaches a peak value of $2000 \mu \mathrm{m}$ at $190 \mathrm{~min}$ ). The ice crystals in such SIPs belong to the aggregation tail of the PSDs in the middle of the cloud. There is a sharp increase in the number of collisions for SIP 4 with other cloud particles in the intermediate cloud region (below $320 \mathrm{hPa}$ ). This leads to a spread of its sedimentation velocity and that of the existing ice particles, increasing the probability of aggregation for SIP 4.

Aggregation increases the geometric area and hence the terminal fall speed of ice crystals. Therefore, if an ice crystal has aggregated once, further collisions with other ice crystals become more likely. This self-enhancing effect causes the very steep increase in the number of aggegation events of SIP 4 seen in Figure 9.

Surprisingly, SIP 3 evolves completely differently, although it originates from the same region as SIP 4. Ice crystals in SIP 3 only grow to maximum dimensions of $200 \mu \mathrm{m}$ at $t=220 \mathrm{~min}$. Turbulent fluctuations induce different homogeneous freezing rates in the nucleation zone. Therefore, young ice crystal concentrations vary considerably there. Depositional growth is inefficient in areas with high $n_{\mathrm{i}}$, because the supersaturation is more rapidly quenched. This is the case for SIP 3, which therefore grows only slowly, in contrast to SIP 4. As a result, SIP 3 does not sediment as far downward into the cloud, and aggregation is less likely to occur than in SIP 4 (the number of aggregation events is zero for SIP 3, but reaches 20 for SIP 4).

Inspecting the number of aggregation events for $\sim 5000$ analysed SIPs, we find a maximum of 23, and an average value below 5 . This is in good agreement with observed values from the literature (Harimayo and Kawasota, 2001). We have verified that the CPI imagery supports this result by showing that the observed aggregates were indeed composed of only a handful of monomers. This greatly increases confidence in the quality of our simulation.

In summary, the formation of very large $(>1000 \mu \mathrm{m})$ ice crystals found in lower regions of stratiform cirrus clouds depends on the conditions for nucleation and early growth of ice crystals in the upper cloud regions. The prevailing growth regime determines whether initially small ice crystals grow large enough to quickly sediment to lower cloud regions, where collisions with pre-existing ice particles must occur for aggregation to proceed efficiently. Controlling factors include the vertical distribution and evolution of temperature and moisture, as well as the associated evolution of the cloud-scale vertical wind field and thus the degree of small-scale dynamical cooling. These ingredients suffice to simulate cirrus in general agreement with the present observations, even in a simplified dynamical secenario that includes only homogeneous freezing. Nevertheless, a number of uncertainties remain (section 7); to better constrain this type of simulation, improved in situ measurements of air motion and supersaturation variability in the vertical profile, number concentrations of small ice crystals, and IN activity are needed.

The presence of IN may modify, but is unlikely to change, this general picture. On the one hand, it would be difficult to explain ice crystal concentrations above about $0.02 \mathrm{~cm}^{-3}$ solely with IN due to their limited abundance in the atmosphere in background conditions (DeMott et al., 2003; Haag et al., 2003b). Concomitant measurements are required to determine the actual IN number concentrations during cirrus formation. On the other hand, depending on temperature, low IN concentrations (in our base case below $0.02 \mathrm{~cm}^{-3}$ ) will not prevent the supersaturation from rising to homogeneous freezing levels.

\subsection{Enhanced aggregation efficiency in the sublimation zone}

The moisture field in the baseline simulation is initially considerably subsaturated $\left(S_{\mathrm{i}} \sim 0.6\right)$ around $360 \mathrm{hPa}$ (Figures 3 and 5). We conjecture that the aggregation frequency is increased in this dry layer. To quantify the frequency of aggregation, we tracked the number of aggregation events per particle in each grid box volume and show in Figure 10(a) the ratio of the number concentration of ice crystal aggregates to the total ice crystal number concentration, $n_{\mathrm{agg}} / n_{\mathrm{i}}$, and in Figure $10(\mathrm{~b})$ the total ice crystal number concentration, $n_{\mathrm{i}}$, versus air pressure at different times.

Over the time span of $16 \mathrm{~min}$, the number ratio increases from 0.15 to 0.48 in the dry layer below $350 \mathrm{hPa}$, in contrast to the upper cloud region where the ratio stays almost constant (but below 0.1). Ice crystals sediment into the dry layer and start to sublimate at $t=50 \mathrm{~min}$. The sedimentation velocities of the crystals decrease and the water vapour supply moistens the air there $\left(S_{\mathrm{i}}\right.$ increases towards saturation; Figure $10(\mathrm{c}))$. As a result, the ice crystals entering the layer at a later time fall faster than the previous ones, leading to the formation of a cirrus microlayer, i.e. a vertically thin layer $(\sim 100 \mathrm{~m})$ composed of medium-sized $(D \approx 100 \mu \mathrm{m})$ ice crystals present in relatively high concentrations $\left(\sim 0.025 \mathrm{~cm}^{-3}\right)$. Comparing the vertical profiles $n_{\mathrm{i}}(p)$ (Figure $10(\mathrm{~b})$ ) at different times reveals the progressive thinning of the layer which peaks at $n_{\mathrm{i}}=0.025 \mathrm{~cm}^{-3}$ at $355 \mathrm{hPa}$ and $t=66 \mathrm{~min}$, a value comparable to the number concentration of homogeneously nucleated ice particles that have formed near $330 \mathrm{hPa}$ and $t=50 \mathrm{~min}$.

This interpretation is supported by the distributions of sedimentation velocities, $v_{t}$, of ice crystals, displayed in Figure 11 for 50 and $66 \mathrm{~min}$. In Figure 11(a), the SIPs are at first above the subsaturated layer and partly sediment into the moistened, subsaturated layer at the later time (mean $v_{\mathrm{t}}$ and spread of the distribution increase). In Figure 11(b), the SIPs have already entered the subsaturated layer below $350 \mathrm{hPa}$ at $50 \mathrm{~min}$ and sublimate later (mean $v_{\mathrm{t}}$ decreases). 

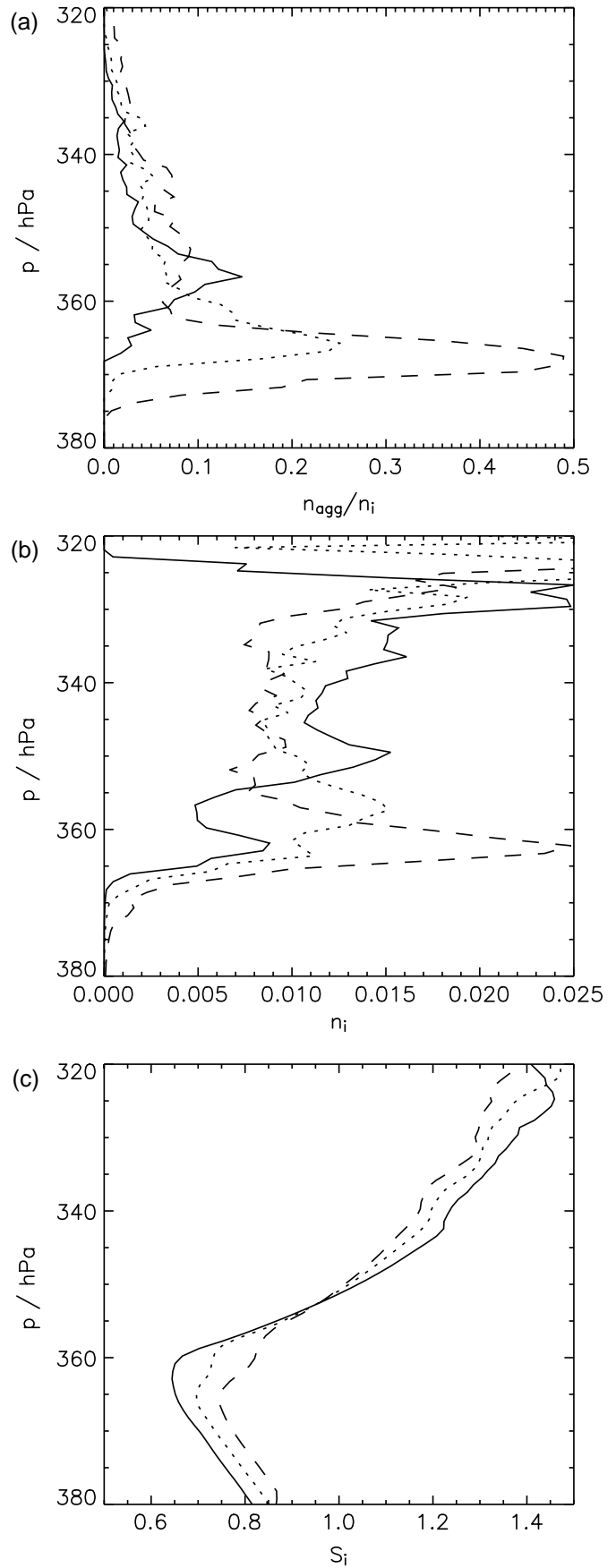

Figure 10. Vertical profiles of (a) the ratio of number concentration of aggregates to that of all ice crystals, $n_{\text {agg }} / n_{\mathrm{i}}$, (b) total ice crystal number concentration $n_{\mathrm{i}}$, and (c) $S_{\mathrm{i}}$, at $50 \mathrm{~min}$ (solid), $58 \mathrm{~min}$ (dotted) and $66 \mathrm{~min}$ (dashed) in the base case. While $n_{\mathrm{agg}} / n_{\mathrm{i}}$ increases with time, the region in which many aggregates form narrows (indicated by the decreasing width of the peak in $n_{\mathrm{i}}$ ), leading to the formation of a sublimation microlayer (see text).

Corresponding snapshots of the 2D distributions of cloud ice water mass fluxes, sedimentation speeds, and other cloud variables are shown in Figure 3 at 50 and 66 min. Sublimation of small ice crystals also occurs in the sublimation layer, reducing $n_{\mathrm{i}}$, but this is not identified as the main reason for the increase in $n_{\mathrm{agg}} / n_{\mathrm{i}}$.

\section{Sensitivity studies}

The meteorological database is not sufficient to fully reconstruct the atmospheric state during cloud evolution
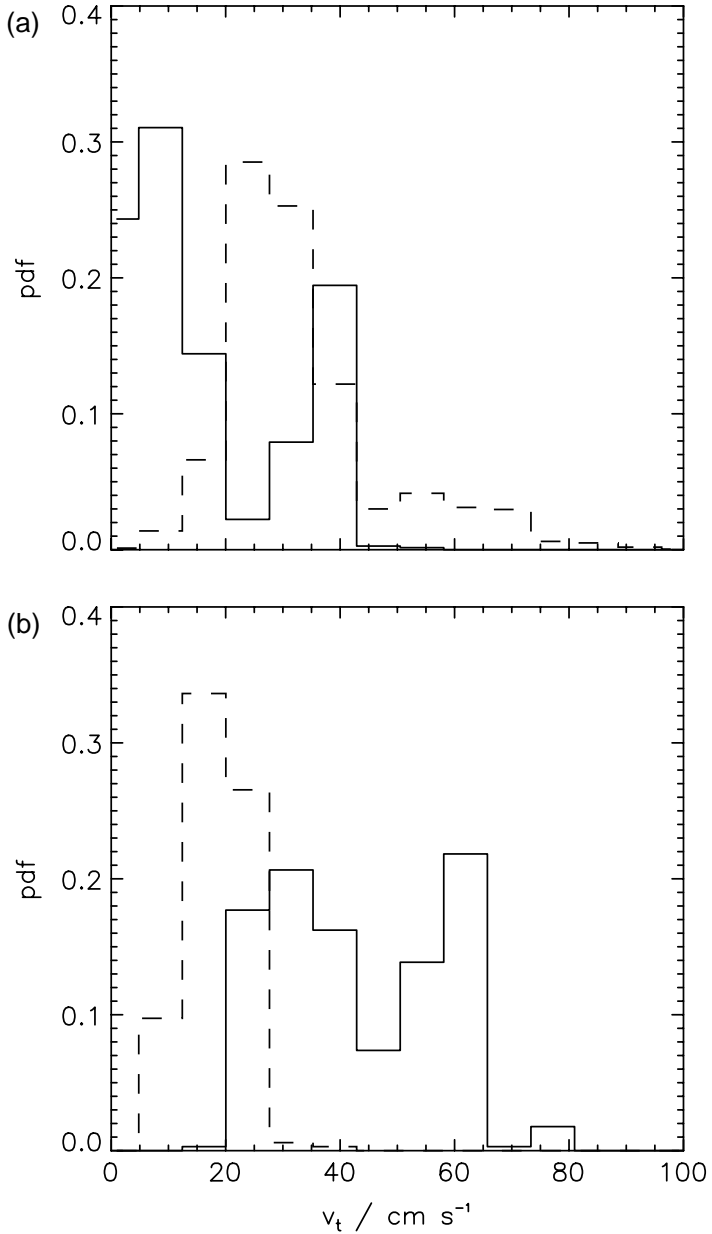

Figure 11. Probability distributions of sedimentation velocities $v_{\mathrm{t}}$ at $50 \mathrm{~min}$ (solid) and $66 \mathrm{~min}$ (dashed) (a) above the subsaturated layer and (b) within the subsaturated layer below $350 \mathrm{hPa}$. See text for further detail.

(particularly at the cloud scale) and we have already pointed out uncertainties in some of the key microphysical processes. We performed a series of 27 sensitivity runs and thereby study results obtained under variation of numerical and lesswell-known meteorological and microphysical parameters. We define plausible ranges for the imposed parameter variations, deduced from measurement uncertainties or guided by uncertainties in the description of microphysical processes and particle characteristics.

\subsection{Domain-integrated (mean cloud) optical depth}

Changing parameters in the sensitivity runs results in a change of the number and position of SIPs, causing statistical noise in the simulated ice phase quantities. Integral properties of the cirrus are more easily intercomparable than local quantities (SK10), because average values are much less affected by statistical noise.

In order to compare the results from different sensitivity studies, we introduce the domain-integrated optical depth $\bar{\tau}$ (also referred to as mean cloud optical depth):

$$
\bar{\tau}=\frac{1}{n} \sum_{k=1}^{N h} \tau_{k}, \quad \tau_{k}=\int \beta_{k}(z) \mathrm{d} z
$$

to judge the impact of parameter variations. In Eq. (1), $\mathrm{Nh}$ is the number of horizontal grid points. At the same 
time, $\bar{\tau}$ serves as a measure of the cloud radiative impact. (The underlying mean cloud ice water path and effective ice crystal size as shown in Figure 2 are defined accordingly.) The solar optical depth, $\tau_{k}$, of a vertical column reflects the short wave radiative properties of the cirrus and combines information on the cloud ice water path via IWC, on ice crystal sizes and habits via the effective size, $D_{\text {eff }}$, and on the vertical extension of the cloud.

Using a constant, size-averaged extinction efficiency of 2 in the solar spectrum (a safe choice for ice crystals larger than a few $\mu \mathrm{m}$ ), we compute the extinction, $\beta_{k}$, (Hansen and Travis, 1974) and the effective particle size, $D_{\text {eff }}$, (Yang et al., 2005) in each grid box at altitude $z$ :

$$
\begin{aligned}
\beta_{k}(z) & =3 \frac{\mathrm{IWC}}{\varrho D_{\mathrm{eff}}}, \\
D_{\mathrm{eff}}= & \frac{3}{2} \frac{\sum_{i=1}^{N_{p}} V_{i}\left(\Pi_{i}, D_{i}\right) \mathcal{N}_{i}}{\sum_{i=1}^{N_{p}} A_{i}\left(\Pi_{i}, D_{i}\right) \mathcal{N}_{i}},
\end{aligned}
$$

where $\varrho$ is the bulk ice mass density, $\Pi_{i}$ denotes the ice crystal habit, $N_{p}$ is the total number of SIP in a grid box, and $V_{i}$ and $A_{i}$ are the crystal volume and projected area, respectively.

To quantify the deviation of a sensitivity run $S$ from the base case $B$, we determine the relative deviation of $\bar{\tau}$ as function of time

$$
\Delta \tau(t)=\frac{\bar{\tau}_{\mathrm{S}}(t)-\bar{\tau}_{\mathrm{B}}(t)}{\bar{\tau}_{\mathrm{B}}(t)} .
$$

Table II summarises the results of the different sensitivity runs. In the last two columns, the temporal mean $\overline{\Delta \tau}$ and standard deviation of $\Delta \tau(t)$ are provided along with the median $\widetilde{\Delta \tau}$ and 20 and 80 percentiles. Deviations $\overline{\Delta \tau}$ are especially large if in one run no crystals are present, while there are many cloudy grid boxes in the other run.

Variations in the numerical parameters do not seriously affect $\overline{\Delta \tau}$; the changes are mostly well below $1 \%$ (section 7.2 and Table II). Among the parameters exerting the strongest sensitivity in the present study (changes in $|\overline{\Delta \tau}|$ exceeding $20 \%$ ) are (in the order of their relevance) the magnitude of the updraught speed (runs A1, A2), the supersaturation (B1, B2), and the possible impact of IN (run J) (sections 7.3 and 7.4).

\subsection{Variation of numerical parameters}

An essential numerical parameter in the LPT approach is the number of SIPs, which depends on details of the model setup (SK10). As noted above, every change in meteorological, microphysical, or numerical parameters implies changes in the number and position of the SIPs tracked in the model and, hence, causes slight differences in the cloud evolution. The results of further studies could therefore, in principle, be masked by a change in sampling statistics. We clarify this issue first.

We performed five sensitivity runs (N1-N5) by varying the number of SIPs between $-80 \%$ and $+40 \%$ relative to the base case. This interval covers the range in the number of tracked particles in all other sensitivity runs. The corresponding deviations $\overline{\Delta \tau}$ are small (below $\pm 1 \%$ ), implying that our base case contains a sufficient number of SIPs to produce robust domain-integrated quantities and that deviations in the sensitivity runs are only marginally affected by this statistical issue.

Concerning variations in the vertical resolution, time step, and the time between subsequent calls of the radiative transfer model, doubling the vertical resolution (i.e. halving the value of $\Delta z$, run $\mathrm{M}$ ), or doubling the temporal resolution (i.e. halving the time steps of all dynamical and microphysical processes, run L), or doubling the time interval during which the net radiative heating terms are updated (run K), result in only small deviations from the base case $(|\overline{\Delta \tau}| \sim 1 \%)$, indicating that these parameters have been chosen properly.

We conclude that the EULAG-LCM baseline simulation is very insensitive to variations of the numerical parameters, so that changes in the results from all other sensitivity simulations discussed below are closely related to the respective changes of meteorological and microphysical parameters directly affecting physical processes.

\subsection{Variation of meteorological parameters}

According to Table II, the evolution of the simulated cirrus cloud is most sensitive to the imposed vertical wind speed (baseline value $w_{0}=0.055 \mathrm{~m} \mathrm{~s}^{-1}$ ). Additional/reduced uplift (run A1/A2) causes enhanced/reduced adiabatic cooling and more/fewer liquid aerosol particles freezing homogeneously. As a result, we find a strong increase/decrease of $n_{\mathrm{i}}$ and $\overline{\Delta \tau}$. These marked sensitivities, around $\pm 80 \%$ for $\overline{\Delta \tau}$, confirm the paramount role of dynamical variability on small spatial and temporal scales on the formation of ice and the further evolution and radiative impact of cirrus (Kärcher and Ström, 2003).

Another key sensitivity is tied to the magnitude of the imposed supersaturation. In runs $\mathrm{B} 1$ and $\mathrm{B} 2$, the entire initial vertical $S_{\text {i }}$ profile was shifted by $\pm 10 \%$. Such changes correspond to the largest nominal absolute errors of the radiosonde data (Figure 5). Deviations at individual altitude levels in nature may have been even larger. The imposed $S_{\mathrm{i}}$ changes exert a strong impact on the nucleation and growth of the crystals. The resulting changes in $\overline{\Delta \tau}$ are substantial, of the order of $\pm 40 \%$.

The effect of vertical wind shear is rather small, despite a variation of $\pm 50 \%$ in runs $\mathrm{C} 1$ and $\mathrm{C} 2$. The range for the deviation in the mean cloud optical depth stays below $6 \%$, in general agreement with results from the literature (Marsham and Dobbie, 2005), but it is possible that the assumption of periodic boundary conditions affects this issue.

The feedback from radiation on the evolution of this cloud is small (run $\mathrm{D}, \overline{\Delta \tau} \sim 2 \%$ ). As mentioned in section 5, diabatic rates are dominated by latent heat release at cloud top and cloud base, respectively. The latent heat changes outweigh the diabatic effects caused by absorption of solar or absorption and emission of infrared radiation in the present case, in part due to the relatively high temperatures $(>215 \mathrm{~K})$. Latent heat effects scale with the ice saturation vapour pressure and become very small at low temperatures, in particular close to the tropopause. In other cases, radiatively induced diabatic effects may become more relevant, depending on the time-scale, cirrus optical depth, and a number of environmental factors controlling the radiative response of thin cirrus.

Radiative effects on ice particle growth and sublimation (run I) exert only a very small impact on the optical depth 
Table II. Summary of the sensitivity analysis for the case-study ARM IOP on 9 March 2000. Parameter settings of the base case are provided in Table I.

\begin{tabular}{|c|c|c|c|c|c|c|}
\hline $\begin{array}{l}\text { Run } \\
\text { identifier }\end{array}$ & $\begin{array}{l}\text { Parameter } \\
\text { being varied }\end{array}$ & $\begin{array}{c}\text { Typical } \\
\text { variation }\end{array}$ & $N_{\text {SIP }}\left(\times 10^{6}\right)$ & $\overline{\Delta \tau} \pm \sigma(\%)$ & \multicolumn{2}{|c|}{$\widetilde{\Delta \tau}(P 20, P 80)(\%)$} \\
\hline \multicolumn{7}{|c|}{ Meteorological parameter } \\
\hline A1 & $w_{0}\left(\mathrm{~m} \mathrm{~s}^{-1}\right)$ & $+0.02 \mathrm{~m} \mathrm{~s}^{-1}(+33 \%)$ & 11.8 & $+88.69 \pm 58.78$ & $+84.24(+43.19$ & $+133.08)$ \\
\hline A2 & & $-0.02 \mathrm{~m} \mathrm{~s}^{-1}(-33 \%)$ & 7.1 & $-70.54 \pm 12.21$ & $-70.45(-74.80$ & $-59.17)$ \\
\hline B1 & $S_{\mathrm{i}}$ & $+10 \%$ & 10.8 & $+45.18 \pm 64.81$ & $+37.63(+4.72$, & $+72.63)$ \\
\hline B2 & & $-10 \%$ & 13.7 & $-40.37 \pm 25.29$ & $-40.74(-53.85$ & $-9.01)$ \\
\hline $\mathrm{C} 1$ & $\partial u / \partial z\left(s^{-1}\right)$ & $+0.001 \mathrm{~s}^{-1}(+50 \%)$ & 11.9 & $-0.80 \pm 21.17$ & $+4.15(+1.78$ & $+7.59)$ \\
\hline $\mathrm{C} 2$ & & $-0.001 \mathrm{~s}^{-1}(-50 \%)$ & 12.9 & $-5.66 \pm 8.27$ & $-3.48(-4.73$ & $-1.73)$ \\
\hline $\mathrm{D}$ & Radiation & off $(-100) \%$ & 12.7 & $+1.55 \pm 2.39$ & $+1.73(+0.89$ & $+2.64)$ \\
\hline $3 \mathrm{D}$ & $3 \mathrm{D}$ run & $+1 D$ & 535.0 & $-15.29 \pm 6.27$ & $-13.54(-19.28$ & $-8.88)$ \\
\hline \multicolumn{7}{|c|}{ Microphysical parameter } \\
\hline E1 & Habit $\Pi_{i}$ & $\mathrm{C} 2 \mathrm{a}$ & 11.5 & $+11.15 \pm 10.29$ & $+9.54(+5.69$ & $+13.53)$ \\
\hline E2 & & C1e $(60 \%)$ & 10.9 & $-11.57 \pm 3.15$ & $-11.90(-12.45$ & $-9.93)$ \\
\hline $\mathrm{F} 1$ & $v_{\mathrm{t}}$ & $+50 \%$ & 11.2 & $-7.79 \pm 4.61$ & $-7.86(-11.94$ & $-4.63)$ \\
\hline $\mathrm{F} 2$ & & $-50 \%$ & 14.2 & $+5.94 \pm 5.19$ & $+7.00(+1.82$ & $+11.45)$ \\
\hline G1 & $E_{\mathrm{a}}$ & $+0.25(+33 \%)$ & 12.5 & $-3.43 \pm 2.22$ & $-2.99(-5.54$ & $-0.81)$ \\
\hline G2 & & $-0.25(-33 \%)$ & 12.8 & $+3.39 \pm 2.99$ & $+3.61(+0.73$ & $+6.92)$ \\
\hline G3 & No aggregation & $-0.75(-100 \%)$ & 13.2 & $+10.40 \pm 8.62$ & $+8.69(+3.45$ & $+21.09)$ \\
\hline $\mathrm{H} 1$ & $\alpha_{\mathrm{v}}$ & $+0.5(+100 \%)$ & 12.3 & $-1.77 \pm 0.99$ & $-1.81(-2.33$ & $-1.39)$ \\
\hline $\mathrm{H} 2$ & & $-0.25(-50 \%)$ & 13.2 & $+3.05 \pm 1.59$ & $+3.39(+2.83$ & $+3.95)$ \\
\hline I & $H_{R, i}$ & on $(+100 \%)$ & 12.6 & $-0.78 \pm 1.28$ & $-0.33(-1.94$ & $+0.54)$ \\
\hline $\mathrm{J}$ & Nucleation & +heterogeneous & 34.2 & $-20.29 \pm 49.68$ & $-22.84(-45.53$ & $-3.03)$ \\
\hline \multicolumn{7}{|c|}{ Numerical parameter } \\
\hline $\mathrm{K}$ & $\Delta t$ (radiation) & $+40 \mathrm{~s}(+100 \%)$ & 12.7 & $-0.09 \pm 0.63$ & $-0.09(-0.59$ & $+0.68)$ \\
\hline $\mathrm{L}$ & $\begin{array}{l}\Delta t \text { (dynamics, } \\
\text { microphysics) }\end{array}$ & $-50 \%$ & 18.2 & $+1.05 \pm 1.84$ & $+1.09(-0.12$ & $+1.90)$ \\
\hline M & $\Delta z$ & $-50 \%$ & 26.3 & $-0.97 \pm 11.14$ & $+0.85(-0.42$, & $+3.68)$ \\
\hline $\mathrm{N} 1$ & $N_{\mathrm{SIP}}$ & $+5.5 \times 10^{6}(+40 \%)$ & 18.2 & $-0.32 \pm 0.64$ & $-0.23(-0.56$ & $+0.17)$ \\
\hline $\mathrm{N} 2$ & & $+3.2 \times 10^{6}(+25 \%)$ & 15.9 & $-0.62 \pm 0.76$ & $-0.36(-1.08$ & $+0.07)$ \\
\hline N3 & & $-3.5 \times 10^{6}(-30 \%)$ & 9.2 & $+0.82 \pm 0.94$ & $+1.12(+0.30$ & $+1.40)$ \\
\hline N4 & & $-8.8 \times 10^{6}(-70 \%)$ & 3.9 & $-0.29 \pm 4.65$ & $-0.12(-1.22$, & $+1.67)$ \\
\hline N5 & & $-10.0 \times 10^{6}(-80 \%)$ & 2.6 & $-0.94 \pm 6.96$ & $-1.56(-2.67$ & $+1.65)$ \\
\hline
\end{tabular}

$\overline{\Delta \tau}$ is the temporal mean of $\Delta \tau$ (defined in Eq. (4)), with associated standard deviation $\sigma$.

$\widetilde{\Delta \tau}$ is the corresponding median, with associated 20 and 80 percentiles (in brackets).

C1e hexagonal columns; C2a bullet rosettes

of the cloud $(\overline{\Delta \tau} \sim 1 \%)$. This is conceivable, as those effects become important only in a narrow range around ice saturation. The volume of cloudy air that is close to saturation is small compared to the entire cloud volume, as can be estimated from Figure 3(b, d; contours). We recall that such effects have been entirely neglected in the baseline run (Table I).

The sensitivity analysis has been performed in $2 \mathrm{D}$, because very high resolution meteorological and thermodynamical (numerical or experimental) data have not been available for initialisation. We conducted a full 3D simulation (run 3D) by extending the model domain with 64 grid cells in the third dimension, $y$, using the same horizontal grid spacing, $d y=d x=30 \mathrm{~m}$. We use the same initial vertical profiles as in the $2 \mathrm{D}$ runs for the entire domain. Adding the extra spatial dimension allows us to study the impact of changes in the turbulence scheme on the development of the cloud system.
The number of SIPs tracked corresponds roughly to run N5, so we compare the results to the corresponding simulation. The impact on the optical depth is moderate $(\overline{\Delta \tau} \sim 15 \%)$ compared to changes in the vertical wind speed or the moisture field. The resulting change in $\overline{\Delta \tau}$ is mainly caused by less vigorous updraughts and downdraughts during cloud formation in the $3 \mathrm{D}$ case than in the $2 \mathrm{D}$ run.

\subsection{Variation of microphysical parameters}

In the simulations, the ice crystal habits affect cloud evolution via ice particle sedimentation velocity (directly determined by the habit), ice mass growth rate (various correction factors for the diffusional water vapour uptake rate are habit-dependent), the effective radius entering the radiation code (its definition depends on habit) and the aggregation rate (the effective collision area derived from 
the projected ice particle areas is habit-dependent). We make explicit assumptions about the ice particle habits consistent with the ARM IOP observations, as compiled in Table I. Based on the CPI images, we prescribe the mass- and area-dimensional relationships using empirical relationships (SK10). Neither the exact shape of individual ice crystals, nor the partitioning into different habit categories in the cirrus can be predicted owing to the lack of a physically based treatment of habit evolution.

To study the impact of habit assumptions on $\overline{\Delta \tau}$, we performed two sets of simulations (E1, E2 and F1, F2). In run $\mathrm{E} 1$, we increase the amount of hexagonal columns in the imposed particle habit mix from $30 \%$ to $60 \%$. In run E2, we alter the mass-dimensional power law coefficient for bullet rosette-shaped crystals from the one presented in Heymsfield et al. (2002) to that of Mitchell (1996). In runs E1 and E2, the habit-induced changes simultaneously affect sedimentation velocities, ice mass growth rates, ice particle effective radii, and aggregation rate. In runs $\mathrm{F} 1$ and F2 only the sedimentation velocities $v_{\mathrm{t}}$ are changed by $\pm 50 \%$, corresponding to differences of $v_{\mathrm{t}}$ for crystals of equal mass but different habit (Heymsfield and Westbrook, 2010). We use the terminal fall speeds from Mitchell and Heymsfield (2005) in our simulations (SK10), but point out that substantial uncertainties (up to a factor of 2) remain in specifying fall speeds for aggregates (Heymsfield and Westbrook, 2010). The factor of 2 motivates changes of the fall speed by $\pm 50 \%$ in the cases F1 and F2.

We find that the particle habit has a limited impact on the simulated mean cloud optical depth (changes about $\pm 10 \%$ ) for E1 and E2. From F1 and F2 (changes about $\pm 7 \%$ ), we conclude that the above habit-induced changes of $\overline{\Delta \tau}$ of at most $\pm 12 \%$ are largely caused by resulting changes of the sedimentation velocities. The changes induced by the habit-dependence of the other variables (as noted above) are much smaller. In cloud-resolving models, it is therefore important to use accurate values for the terminal fall speeds and to maintain consistency between microphysical and optical processes with the assumed habits.

The deposition coefficient for water vapour on ice, $\alpha_{\mathrm{v}}$, controls the growth rate of small $(\sim 1 \mu \mathrm{m})$ ice particles (sizes comparable to the mean free path of air molecules in the upper troposphere), e.g. during the nucleation phase (Kärcher and Lohmann, 2002). In the literature, a large range of values $0.01-1.0$ (Peter et al., 2006) has been noted, but the values from different studies are not always intercomparable (since supersaturation levels, ice-forming nuclei composition and size, and other crucial parameters are different).

Variations of $\alpha_{\mathrm{v}}$ between 0.25 and 1 (runs $\mathrm{H} 1$ and $\mathrm{H} 2$ ) only slightly modify the simulated $\overline{\Delta \tau}$ values (within $\pm 3 \%$ ). This is because depositional growth takes place mostly in the diffusion regime, which is not affected by $\alpha_{\mathrm{v}}$. We find a significant influence of the deposition coefficient for a major reduction to $\alpha_{\mathrm{v}}=0.05$. The change in mean cloud optical depth then increases to $\sim 30 \%$. In this case, the depositional mass growth rate is influenced by gas kinetic effects and scales almost linearly with $\alpha_{\mathrm{v}}$ for small ice particles shortly after ice nucleation. However, with such a small $\alpha_{\mathrm{v}}$ value, we do not reproduce the observed ice particle concentrations any longer. Instead, too many ice particles form which generally stay too small. These results are broadly consistent with earlier comparisons between models and observational studies (Kärcher and Ström, 2003; Haag et al., 2003a).
For the base case, we assume homogeneous freezing as the sole pathway for ice formation (section 4.1). In run J we additionally prescribe a spatially homogeneous population of bare mineral dust deposition IN with an assumed total number concentration of $n_{\mathrm{p}}=0.002 \mathrm{~cm}^{-3}$, within the range of values representing background conditions, as motivated by other atmospheric observations (DeMott et al., 2003; Haag and Kärcher, 2004). The present field observations provide no clues to whether IN had been present at all.

The nucleation properties of the IN in our model are taken from laboratory measurements of mineral dust aerosols (Möhler et al., 2006). The corresponding formation rate of ice crystals is

$$
\frac{\mathrm{d} n_{\mathrm{i}}}{\mathrm{d} t}=\zeta \frac{\mathrm{d} S_{\mathrm{i}}}{\mathrm{d} t} n_{\mathrm{p}}
$$

where $\zeta=3.3$ characterizes the IN activation spectrum, i.e. the fraction of IN nucleating ice in a given range of supersaturation. A steeper activation spectrum results in higher $\zeta$ values, and $\zeta$ also contains information on the threshold ice saturation ratio, $S_{0}$, for the onset of heterogeneous ice nucleation. In run J, we use the lowest value suggested by the laboratory data, $S_{0}=1.04$. Such a low value of $S_{0}$ triggers ice formation much earlier than in the baseline simulation. The largest changes in $\Delta \tau$ are simulated in the first hour of cirrus formation. The quenching of the supersaturation by the heterogenously formed ice crystals delays homogeneous freezing of supercooled liquid aerosol droplets. As soon as homogeneous frezing commences, $\bar{\tau}$ starts to increase rapidly and the subsequent evolution of the mean cloud optical depth becomes similar to the base case, i.e. the influence of IN diminishes during the aging of the cloud. Thus, the rather large values of $\overline{\Delta \tau}$ and $\widetilde{\Delta \tau}$ mainly arise in the early stage of the cloud evolution.

In section 5 we noted that some of the observed large particles in the base case were lacking in the upper cloud region. We attributed this to an overlying thin cirrus cloud. The inclusion of efficient IN does trigger additional ice formation at locations where the homogeneous freezing threshold is not reached. Figure 8 supports this notion. In this case, with IN included in the simulation (Figure $8(\mathrm{~b})$ ), large ice crystals with maximum dimensions up to $2000 \mu \mathrm{m}$ are present in the PSD in the uppermost spiral (lower red-dashed curves). The initial vertical profile of $S_{\mathrm{i}}$ (Figure 5(a)) limits the role of IN to nucleate ice at lower levels $(400-450 \mathrm{hPa})$ unless these IN nucleate ice already slightly above saturation.

We point out that IN concentrations $>0.01 \mathrm{~cm}^{-3}$ would begin to supress homogeneous freezing in our simulations, in which case we would start to disagree considerably with the observations. As this upper limit IN concentration is within the expected range of tropospheric background IN concentrations $<0.01-0.03 \mathrm{~cm}^{-3}$ in northern midlatitudes (DeMott et al., 2003; Haag et al., 2003b), and the actual IN concentrations have not been measured during the ARM IOP, we cannot rule out that the evolution of the real cloud system was indeed influenced (but unlikely controlled) by a small number of IN, such as prescribed in run J. We recall that ice forms very early (slightly above saturation in run J). Coating IN with layers of supercooled solutions may increase $S_{0}$ towards the high homogeneous freezing levels (Cziczo et al., 2009). Details depend sensitively on the assumed updraught speed, initial supersaturation, and on the IN composition (ice nucleation mechanism). 

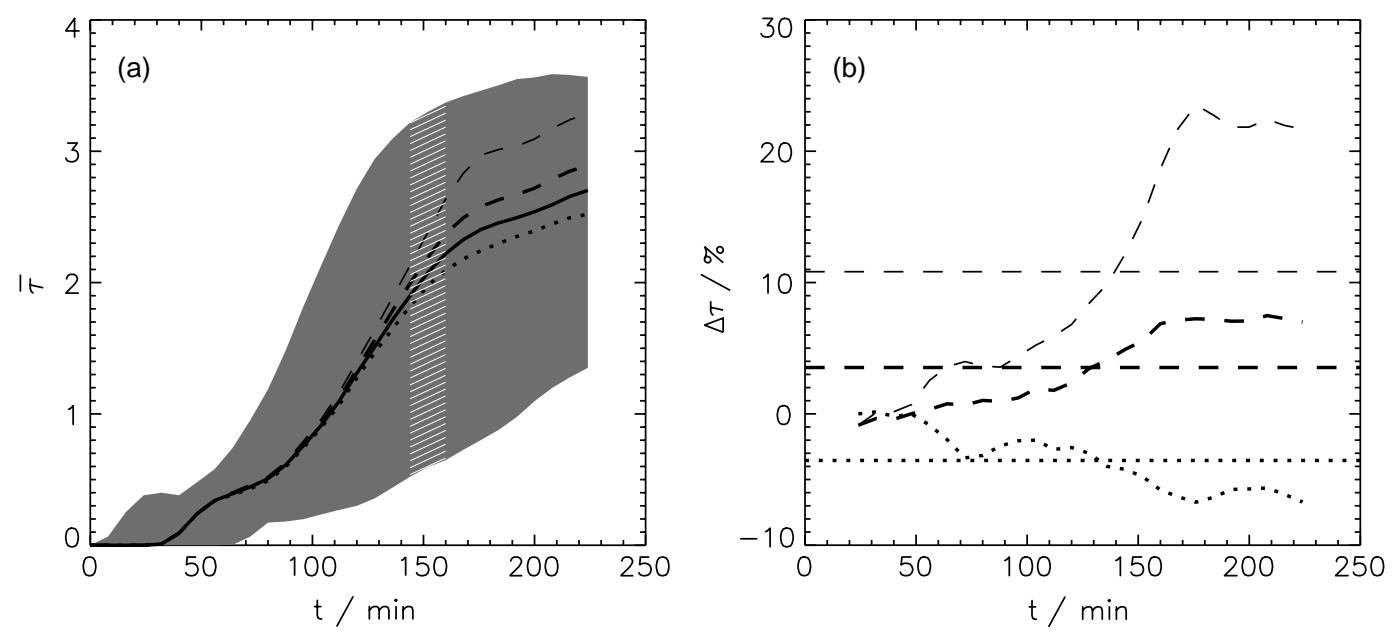

Figure 12. (a) shows the temporal evolution of the domain-integrated (mean cloud) optical depth, $\bar{\tau}$, in the baseline case (solid curve, $E_{\mathrm{a}}=0.75$ ) and in the sensitivity runs G1-G3 (other curves). The most efficient aggregation $E_{\mathrm{a}}=1$ occurs in run G1 (dotted), and no aggregation in run G3 (dashed thin, $E_{\mathrm{a}}=0$ ); run G2 is the intermediate case (dashed bold, $E_{\mathrm{a}}=0.5$ ). The grey shaded area covers the evolution of $\bar{\tau}$ for all sensitivity studies compiled in Table II. The white hatched area indicates the time window where the simulated cirrus most likely passed the CF and observations of $\bar{\tau}$ are available (Comstock et al., 2007), which hint at $2<\bar{\tau}<3$. (b) shows the relative deviation $\Delta \tau(t)$ from the baseline case and corresponding temporal means $\overline{\Delta \tau}$ (horizontal lines).

In summary, we found that none of the sensitivity studies led to a better overall agreement with the observations than our baseline simulation. To make progress in future work, several of the uncertain meteorological and aerosol-related parameters need to be better constrained by observations.

\subsection{Influence of the aggregation efficiency on the aggregation process and cloud evolution}

In the sensitivity runs G1-G3, the constant aggregation efficiency parameter, $E_{\mathrm{a}}$, was varied between 0 and 1 to study the impact of aggregation on cloud evolution. Aggregation becomes increasingly likely as $E_{\mathrm{a}}$ increases, leading to the formation of larger clusters that sediment more quickly.

Figure 12 shows the temporal evolutions of the mean cloud optical depth, $\bar{\tau}(t)$, and the relative deviations $\Delta \tau(t)$ from the base case. (The underlying domain-integrated ice water path and effective size are shown in Figure 2.) Shutting off aggregation entirely in run G3 $\left(E_{\mathrm{a}}=0\right)$ contradicts the aircraft measurements (Figure 13). Upon increasing $E_{\mathrm{a}}, \bar{\tau}$ decreases, especially at later times. Furthermore, the width of the entire PSD broadens because the spread of the large particle mode $(D>500-700 \mu \mathrm{m})$ increases (Figure 13). The large particles from run $\mathrm{G} 1\left(E_{\mathrm{a}}=1\right)$ sediment most rapidly, enhancing the ice mass flux from the upper and middle part of the cirrus to the lower (subsaturated) regions. Thus, the enhanced aggregation efficiency $E_{\mathrm{a}}$ contributes to an enhanced reduction of ice crystal number and mass concentration in this case. This explains the successive reduction of $\bar{\tau}$ at later times in the simulations $\mathrm{G} 3 \rightarrow \mathrm{G} 2 \rightarrow \mathrm{G} 1$ $\left(E_{\mathrm{a}}=0 \rightarrow 0.5 \rightarrow 1\right)$. If the ice-supersaturated layer was vertically thinner (thicker) than modelled, the mean cloud optical depth would correspondingly be smaller (larger) and the effect of varying $E_{\mathrm{a}}$ on $\bar{\tau}$ would be more (less) pronounced. However, for (geometrically) thin cirrus, aggregation is expected to be less effective.

From the PSDs shown in Figure 13, we confirm the importance of the aggregation process to explain the exponential aggregation tail for particles with $D>500-700 \mu \mathrm{m}$. Without aggregation (run G3), we do not obtain a large ice crystal mode and the PSD drops sharply at $D \approx 500 \mu \mathrm{m}$.
This disagrees with the observations and implies that the PSD evolves in two distinct growth regimes. Depositional growth mainly characterizes the shape of the PSD at the small size end, while the exponential large size tail is controlled by aggregation processes (in the absence of liquid water, as observed). In the presence of supercooled liquid cloud or raindrops, riming and perhaps ice crystal break-up may additionally affect the PSD. Furthermore, the results presented in Figure 8((a) baseline case; (b) run J) demonstrate that the inclusion of few IN modifies the large particle population as well, potentially improving the comparison with some of the observations.

\section{Summary and recommendations for future work}

In the present work, we applied a cloud-resolving model with explicit aerosol and ice microphysics and Lagrangian ice particle tracking to simulate the formation and evolution of a deep stratiform cirrus cloud observed during the US ARM IOP on 9 March 2000. The aircraft data sampling procedure (drifting Lagrangian spiral descent flight tracks) has been repeated in the model to enable the closest possible comparison to these measurements. We have presented a very detailed comparison between simulation results and a number of observations from different platforms (aircraft, active remote sensing instruments, and radiosondes).

Our model is capable of explaining the evolution of the cirrus over $4 \mathrm{~h}$ and predicting most of the observed cloud properties. Homogeneous freezing was found to be the major pathway for ice formation, leading to total, averaged ice crystal concentrations of $0.1 \mathrm{~cm}^{-3}$ of air in upper cirrus formation regions. We confirm the paramount role of dynamical variability on small spatial and temporal scales in determining the formation of ice and the further evolution and radiative impact of cirrus. The factors controlling aggregation, i.e. the formation of large, precipitating ice crystals, were investigated. A comprehensive sensitivity analysis pointed at several meteorological and microphysical parameters to which the simulated cloud properties were most sensitive. Therefore, the results of this study may serve as a guide for designing modelling (including theory) 


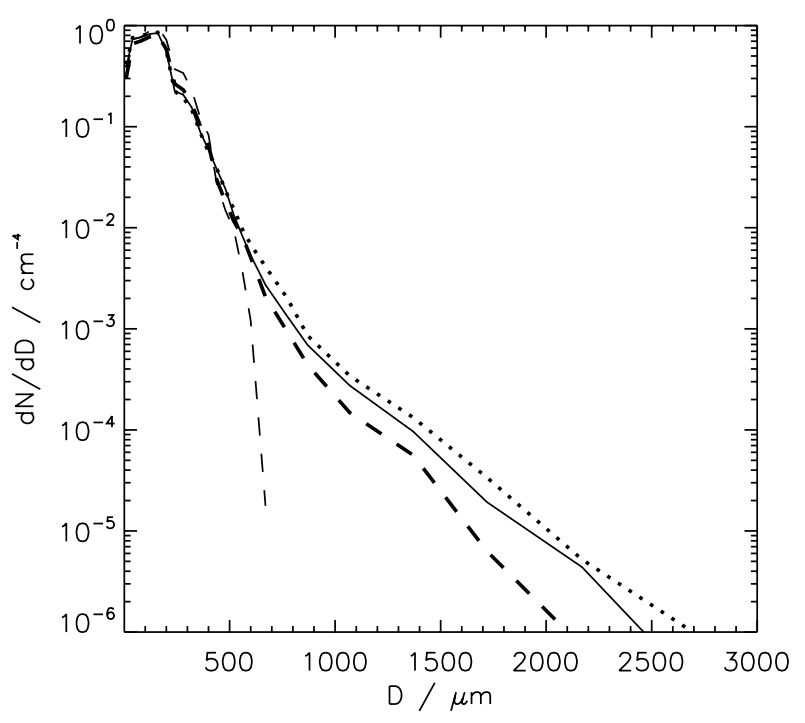

Figure 13. Mean ice particle size distributions sampled over all cloudy grid boxes from sensitivity runs G1-G3 and the base case in the mature cloud stage roughly $3 \mathrm{~h}$ after formation (at $t=168 \mathrm{~min}$ ). Line styles are as in Figure 12. The case without aggregation (G3, thin dashed curve) only predicts the small mode, in striking contrast to the field measurements (Figure 8).

and observational strategies (including laboratory and field measurements) in future work.

We directly simulated aggregation due to differential sedimentation for the first time on a particle-by-particle basis in a realistic cloud environment. This process needs to be included in order to explain the existence of ice crystals with maximum dimensions $>500-700 \mu \mathrm{m}$, as observed in the field study. On average, modelled and observed aggregates contain about five pristine ice crystals. The process-based treatment of aggregation demonstrates that the formation of very large ( $>2000 \mu \mathrm{m}$ ) ice crystals present in the lower cirrus cloud regions depends on the conditions for nucleation and early growth of ice crystals in the upper cloud regions and requries vertically extended cloud regions. It is not necessary to invoke the presence of heterogeneous IN for aggregation to proceed efficiently.

Our simulations point at very efficient aggregation in the relatively dry sublimation zone of deep cirrus. This is because ice crystals sediment into (subsaturated) regions with an enhanced water vapour content (which leads to an increase of their fall speeds relative to the motion in the same layer without enhanced moisture). The enhanced moisture originates from the sublimation of preceding ice crystals (which leads to a decrease of their fall speeds, so that they can be captured by the faster sedimenting ice crystals). This mechanism causes the formation of a very narrow $(100 \mathrm{~m})$ sublimation microlayer in the simulated cloud. In this layer, a large fraction $(>50 \%)$ of ice crystals are aggregates and total ice crystal number concentrations there reach values up to $\sim 0.02 \mathrm{~cm}^{-3}$.

Future simulations of this type would benefit from advances in theories describing the hydrodynamical and microphysical components of the aggregation efficiency parameter (e.g. size- and habit-dependencies), as well as a physically based treatment of ice crystal habits (including their effect on terminal fall speeds) as a function of crystal structure and environmental conditions affecting the evolution of the shapes of individual ice crystals.
When averaged over the entire developed cloud, ice PSDs exhibit two distinct modes. Each mode repesents a unique growth regime. Diffusional growth (uptake of water vapour from the gas phase) only leads to pristine ice crystals with maximum dimensions of at most $\sim 500 \mu \mathrm{m}$ (the small size mode). The small mode contain the nucleation mode (maximum dimensions roughly $<50 \mu \mathrm{m}$ ). In cirrusgenerating cells, the nucleation mode may control the properties of the small mode. The larger ice particle mode develops via aggregation of pristine ice crystals. The small (large) mode predominantly occurs in upper (lower) cloud layers, but large (small) crystals may be present in upper (lower) cloud layer as well. There is a continuous transition between the two size modes, as no critical threshold exists for the generation of the large mode (as is the case for the production of rain from cloud droplets in warm clouds via collision-coalescence).

We found that the impact of assumed, very efficient IN on the cloud mean optical depth diminished rapidly during aging of the cloud. This strongly suggests that such IN did not control the evolution of the observed cloud system. Uncertainties in other meteorological and microphysical parameters affected the cloud optical depth as much as (or more than) IN. Although we may imagine cases where IN are needed to explain a specific measurement, observational case studies and related model analyses of many more different cirrus cloud types (including thin tropical and polar cirrus) are required to judge whether this finding is globally representative. Only then will it be possible to decide whether it is important to treat IN in great detail in advanced parametrizations of cirrus formation in global climate models. In this regard, we recall that the main purpose of climate models is not to resolve individual clouds, but to capture their mean climate impact, which primarily depends on the cloud optical depth and fractional coverage. The cloud mean optical depth is not sensitive to uncertainties in the aggregation efficiency parameter in the present case, implying that the larger number of small (unaggregated) ice crystals dominated this variable.

Our simulations led to results in agreement with the observations only when using a deposition coefficient $>0.1$ for water vapour molecules impinging on the ice crystal surfaces. Employing lower values significantly overestimates the number concentration of ice crystals from homogeneous freezing. We could not rule out that a small number of heterogeneous IN ( $\leq 10 \ell^{-1}$ of air) could have affected the cirrus cloud in nature. Such low number concentrations would be consistent with previous estimates of the background concentration of heterogeneous IN. Uncertainties remain concerning the use of different values for the deposition coefficient in the case of freezing liquid droplets (requiring high supersaturations) or nucleation of ice at solid particle surfaces (in the case of low superaturations/ice nucleation thresholds).

The authors acknowledge the substantial efforts needed to prepare, organise and perform the observational case-study. Nevertheless, an important lesson learned from the present work is that the database does not allow us to fully constrain simulations at this very detailed level of modelling. We have determined the cloud-scale evolution of the vertical wind field, variability in cooling rates, initial vertical profile of ice supersaturation, number concentrations of small ice crystals from the nucleation mode, and spatial distribution and properties of heterogeneous IN as essential to better understand cirrus formation and development. Therefore, 
those meteorological and aerosol-related parameters also need to be measured in future observations to provide tighter constraints for cirrus cloud-resolving models.

\section{Acknowledgements}

Data were obtained from the ARM program sponsored by the US Department of Energy (DOE). The simulations have been carried out at the European Centre for Medium-Range Weather Forecasts (ECMWF, Reading, UK) and at Deutsches Klimarechenzentrum (DKRZ, Hamburg, Germany). We are grateful to Steven Dobbie and Huiyi Yang (University of Leeds, UK) for managing and guiding the GEWEX GCSS WG 2 and to Andy Heymsfield for helpful comments on a preliminary version of this manuscript. This work was supported in part by the Helmholtz Association of German Research Centres (HGF) Virtual Institute 'Aerosol-Cloud Interactions' (VI-ACI) and by the European integrated project 'Stratosphere-Climate Links With Emphasis on the UTLS' (SCOUT-O3).

\section{Appendix A}

\begin{tabular}{ll}
\hline Abbreviations \\
ARM & Atmospheric Radiation Measurement \\
CF & ARM Central Facility \\
CPI & Cloud Particle Imager \\
CVI & Counterflow Virtual Impactor \\
DLR & Deutsches Zentrum für Luft- und Raumfahrt \\
GCSS & GEWEX Cloud System Study \\
GEWEX & Global Energy and Water Cycle Experiment \\
IN & Ice nuclei \\
IOP & Intensive Operational Period \\
IWC & Ice water content \\
LCM & Langrangian Cirrus Module \\
LES & Large-eddy simulation \\
LPT & Lagrangian ice particle tracking \\
MMCR & Millimetre cloud radar \\
MPL & Micropulse lidar \\
PSD & Particle size distribution \\
SIP & Simulation ice particle \\
UTC & Universal Time Coordinated \\
WG & Working Group \\
\hline
\end{tabular}

\section{Appendix B}

\begin{tabular}{ll}
\hline \multicolumn{2}{l}{ Notation } \\
$A_{i}$ & Ice crystal projected area \\
$c_{p}$ & Specific heat at constant pressure \\
$D, D_{i}$ & Ice crystal maximum dimension \\
$D_{1}$ & $\quad$ Number-weighted mean ice crystal \\
& maximum dimension \\
$D_{g e}$ & Generalized effective size (Fu, 1996) \\
$D_{\text {eff }}$ & Effective ice crystal size \\
$E_{\mathrm{a}}$ & Aggregation efficiency (hydrodynamical \\
& and microphysical contributions) \\
$g$ & $\quad$ Gravitational acceleration \\
$H$ & Cloud height \\
\hline
\end{tabular}

Appendix B (continued)

\begin{tabular}{|c|c|}
\hline$H_{R, i}$ & net heating rate for SIP \\
\hline $\mathrm{i}$ & (subscript) ice \\
\hline$i$ & (subscript) numerical index \\
\hline$n_{\mathrm{i}}$ & Total number concentration of ice crystals \\
\hline$n_{\mathrm{p}}$ & Total number concentration of ice nuclei \\
\hline$N$ & Brunt-Väisälä frequency \\
\hline$N h$ & Number of horizontal grid points \\
\hline$N_{\mathrm{p}}$ & Total number of SIPs in a grid box \\
\hline$N_{\text {SIP }}$ & Total number of SIPs \\
\hline $\mathcal{N}_{i}$ & Number of real ice crystals represented by a SIP \\
\hline$p$ & Air pressure \\
\hline$q_{\mathrm{i}}$ & Ice mass mixing ratio \\
\hline$q_{\mathrm{v}}$ & Water vapour mass mixing ratio \\
\hline$S_{\mathrm{i}}, S_{0}$ & $\begin{array}{l}\text { Ice saturation ratio, onset value for } \\
\text { heterogeneous ice nucleation }\end{array}$ \\
\hline$T$ & Air temperature \\
\hline $\mathcal{T}_{1}$ & $\begin{array}{l}\text { Start time of the comparison } \\
\text { between simulation and measurement }\end{array}$ \\
\hline$\Delta t$ & Dynamical time step \\
\hline$\Delta t_{\mathrm{M}}$ & Microphysical time step $(<\Delta t)$ \\
\hline$\Delta t_{\mathrm{N}}$ & Time step during ice nucleation \\
\hline$\Delta \mathcal{T}$ & Time interval for model output \\
\hline $\mathbf{v}_{\mathrm{t}}$ & Terminal fall velocity \\
\hline$V_{i}$ & Ice crystal volume \\
\hline$w_{0}$ & Updraught velocity \\
\hline$z$ & Vertical coordinate \\
\hline$\alpha_{\mathrm{v}}$ & Deposition coeff. for water vapour on ice \\
\hline$\beta$ & Short wave cloud ice extinction \\
\hline$\epsilon$ & Eddy dissipation rate \\
\hline$\theta$ & Potential temperature \\
\hline$\lambda$ & Wavelength \\
\hline$\Pi_{i}$ & Ice crystal habit \\
\hline$\sigma$ & Standard deviation \\
\hline$\tau$ & Solar optical depth \\
\hline $\bar{\tau}$ & $\begin{array}{l}\text { Domain-integrated or cloud mean } \\
\text { optical depth }\end{array}$ \\
\hline$\Delta \tau$ & $\begin{array}{l}\text { Relative deviation of } \bar{\tau} \text { between the } \\
\text { base case and a sensitivity run }\end{array}$ \\
\hline$\overline{\Delta \tau}$ & Temporal mean of $\Delta \tau$ \\
\hline$\widetilde{\Delta \tau}$ & Median value of $\Delta \tau$ \\
\hline$\Phi$ & Ice mass flux density \\
\hline
\end{tabular}

\section{References}

Anderson GP, Clough SA, Kneizys FX, Chetwynd JH, Shettle EP. 1986. 'AFGL atmospheric constituent profiles $(0-120 \mathrm{~km})$ '. Report AFGL-TR-86-0110. Air Force Geophysical Laboratory: Hanscom AFB, Mass., USA.

Comstock JM, D'Entremont R, De Slover D, Mace GG, Matrosov SY, McFarlane SA, Minnis P, Mitchell D, Sassen K, Shupe MD, Turner DD, Wang Z. 2007. An intercomparison of microphysical retrieval algorithms for upper-tropospheric ice clouds. Bull. Amer. Meteorol. Soc. 88: 191-204.

Cziczo DJ, DeMott PJ, Brooks SD, Prenni AJ, Thomson DS, Baumgardner D, Wilson JC, Kreidenweis SM, Murphy DM. 2004. Observations of organic species and atmospheric ice formation. Geophys. Res. Lett. 31: L12116, DOI: 10.1029/2004GL019822.

Cziczo DJ, Froyd KH, Gallavardin SJ Möhler O, Benz S, Saathoff H, Murphy DM. 2009. Deactivation of ice nuclei due to atmosphercally relevant surface coatings. Environ. Res. Lett. 4: 044013, DOI: 10.1088/1748-9326/4/4/044013. 
DeMott PJ, Cziczo DJ, Prenni AJ, Murphy DM, Kreidenweis SM, Thomson DS, Borys R, Rogers DC. 2003. Measurements of the concentration and composition of nuclei for cirrus formation. Proc. Natl. Acad. Sci. USA 100: 14655-14660.

Field PR, Heymsfield AJ. 2003. Aggregation and scaling of ice crystal size distributions. J. Atmos. Sci. 60: 544-560.

Field PR, Heymsfield AJ, Bansemer A. 2006. Shattering and particle interarrival times measured by optical array probes in ice clouds. $J$. Atmos. Oceanic Technol. 23: 1357-1371.

Fu Q. 1996. An accurate parametrization of the solar radiative properties of cirrus clouds for climate models. J. Climate 9: 2058-2082.

Grabowski WW, Smolarkiewicz PK. 2002. A multiscale anelastic model for meteorological research. Mon. Weather Rev. 130: 939-956.

Haag W, Kärcher B. 2004. The impact of aerosol and gravity waves on cirrus clouds at midlatitudes. J. Geophys. Res. 109: D12202, DOI: 10.1029/2004JD004579.

Haag W, Kärcher B, Schaefers S, Stetzer O, Möhler O, Schurath U, Krämer M, Schiller C. 2003a. Numerical simulations of homogeneous freezing processes in the aerosol chamber AIDA. Atmos. Chem. Phys. 3: $195-210$.

Haag W, Kärcher B, Ström J, Minikin A, Ovarlez J, Lohmann U, Stohl A 2003b. Freezing thresholds and cirrus cloud formation mechanisms inferred from in situ measurements of relative humidity. Atmos. Chem. Phys. 3: 1791-1806.

Hall WD, Pruppacher HR. 1976. The survival of ice particles falling from cirrus clouds in subsaturated air. J. Atmos. Sci. 33: 1995-2006.

Hansen JE, Travis LD. 1974. Light scattering in planetary atmospheres. Space Sci. Rev. 16: 527-610.

Harimayo T, Kawasota Y. 2001. Snowflake formation and its regional characteristics. J. Fac. Sci. Hokkaido Univ. Ser. 7 11: 793-809.

Heymsfield AJ. 2007. On measurements of small ice particles in clouds. Geophys. Res. Lett. 34: L23812, DOI: 10.1029/2007GL030951.

Heymsfield AJ, Westbrook CD. 2010. Advancements in the estimation of ice particle fall speeds using laboratory and field measurements. $J$. Atmos. Sci. 67: 2469-2482.

Heymsfield AJ, Lewis S, Bansemer A, Iaquinta J, Miloshevich LM Kajikawa M, Twohy C, Poellot MR. 2002. A general approach for deriving the properties of cirrus and stratiform ice cloud particles. $J$. Atmos. Sci. 59: 3-29.

Heymsfield AJ, Field PR, Bansemer A. 2008. Exponential size distributions for snow. J. Atmos. Sci. 65: 4017-4031.

Jensen EJ, Toon OB, Westphal DL, Kinne S, Heymsfield AJ. 1994. Microphysical modeling of cirrus 1. Comparison with 1986 FIRE IFO measurements. J. Geophys. Res. 99: 421-442.

Jensen E, Starr D, Toon O. 2004. Mission investigates tropical cirrus clouds. Eos 85: 45-50.

Jensen EJ, Lawson P, Baker B, Pilson B, Mo Q, Heymsfield AJ, Bansemer A, Bui TP, McGil M, Hlavka D, Heymsfield G, Platnick S Arnold GT, Tanelli S. 2009. On the importance of small ice crystals in tropical anvil cirrus. Atmos. Chem. Phys. 9: 5519-5537.

Kärcher B, Lohmann U. 2002. A parametrization of cirrus cloud formation: Homogeneous freezing including effects of aerosol size. J. Geophys. Res. 107: 4698, DOI: 10.1029/2001JD001429.

Kärcher B, Spichtinger P. 2009. Cloud-controlling factors of cirrus In Clouds in the perturbed climate system: Their relationship to energy balance, atmospheric dynamics, and precipitation. Strüngmann Forum Report vol. 2. Heintzenberg J, Charlson RJ. (eds.) MIT Press: Cambridge, Mass., USA.

Kärcher B, Ström J. 2003. The roles of dynamical variability and aerosols in cirrus cloud formation. Atmos. Chem. Phys. 3: 823-838.

Koop T, Luo BP, Tsias A, Peter T. 2000. Water activity as the determinant for homogeneous ice nucleation in aqueous solutions. Nature 406: $611-614$.

Lawson RP, O'Connor D, Zmarzly P, Weaver K, Baker B, Mo Q, Jonsson H. 2006. The 2D-S (stereo) probe: Design and preliminary tests of a new airborne, high-speed, high-resolution particle imaging probe J. Atmos. Oceanic Technol. 23: 1462-1477.
Liou KN, Gu Y, Yue Q, McFarguhar G. 2008. On the correlation between ice water content and ice crystal size and its application to radiative transfer and general circulation models. Geophys. Res. Lett. 35: L13805, DOI: 10.1029/2008GL033918.

Lo KK, Passarelli RE Jr. 1982. Growth of snow in winter storms: An airborne observational study. J. Atmos. Sci. 39: 697-706.

Lynch DK, Sassen, Del Genio A, Heymsfield AJ, Minnis PR, Platt CMR, Quante M, Schumann U, Sundqvist H. 2002. Cirrus - The future. In Cirrus. Lynch DK, Sassen K, Starr DO'C, Stephens G. (eds.) Oxford University Press: Oxford, UK and New York.

Marsham JH, Dobbie S. 2005. The effects of wind shear on cirrus: A large-eddy model and radar case-study. Q. J. R. Meteorol. Soc. 131: 2937-2955.

Miloshevich LM, Vömel H, Paukkunen A, Heymsfield AJ, Oltmans SJ. 2001. Characterization and correction of relative humidity measurements from Vaisala RS80-A radiosondes at cold temperatures. J. Atmos. Oceanic Technol. 18: 135-156.

Miloshevich LM, Vömel H, Whiteman DN, Lesht BM, Schmidlin FI, Russo F. 2006. Absolute accuracy of water vapor measurements from six operational radiosonde types launched during AWEX-G and implications for AIRS validation. J. Geophys. Res. 111: D09S10, DOI: 10.1029/2005JD006083.

Mitchell DL. 1996. Use of mass- and area-dimensional power laws for determining precipitation particle terminal velocities. J. Atmos. Sci. 53: $1710-1723$.

Mitchell DL, Heymsfield AJ. 2005. Refinements in the treatment of ice particle terminal velocities, highlighting aggregates. J. Atmos. Sci. 62: 1637-1644.

Möhler O, Field PR, Connolly P, Benz S, Saathoff H, Schnaiter M, Wagner R, Cotton R, Krämer M, Mangold A, Heymsfield AJ. 2006. Efficiency of the deposition mode ice nucleation on mineral dust particles. Atmos. Chem. Phys. 6: 3007-3021.

Peter T, Marcolli C, Spichtinger P, Corti T, Baker MB, Koop T. 2006. When dry air is too humid. Science 314: 1399-1402.

Raschke E, Flamant P, Fouquart Y, Hignett P, Isaka H, Jonas PR, Sundquist H, Wendling P. 1998. Cloud-radiation studies during the European Cloud and Radiation Experiment (EUCREX). Surv. Geophys. 19: 89-138.

Richardson MS, DeMott PJ, Kreidenweis SM, Petters MD, Carrico CM. 2010. Observations of ice nucleation by ambient aerosol in the homogeneous freezing regime. Geophys. Res. Lett. 37: L04806, DOI: 10.1029/2009GL041912.

Sölch I, Kärcher B. 2010. A large-eddy model for cirrus clouds with explicit aerosol and ice microphysics and Lagrangian ice particle tracking. Q. J. R. Meteorol. Soc. 136: 2074-2093.

Ström J, Seifert M, Kärcher B, Ovarlez J, Minikin A, Gayet J-F, Krejci R, Petzold A, Auriol F, Haag W, Busen R, Schumann U, Hansson HC. 2003. Cirrus cloud occurrence as a function of ambient relative humidity: A comparison of observations obtained during the INCA experiment. Atmos. Chem. Phys. 3: 1807-1816.

Stubenrauch CJ, Eddounia F, Rädel G. 2004. Correlations between microphysical properties of large-scale semi-transparent cirrus and the state of the atmosphere. Atmos. Res. 72: 403-423.

Westbrook CD, Ball RC, Field PR, Heymsfield AJ. 2004. Theory of growth by differential sedimentation, with application to snowflake formation. Phys. Rev. E 70: 021403-10214037.

Westbrook CD, Hogan RJ, Illingworth AJ. 2008. The capacitance of pristine ice crystals and aggregate snowflakes. J. Atmos. Sci. 65: 206-219.

Yang $\mathrm{P}$, Wei $\mathrm{H}$, Huang $\mathrm{H}$, Baum BA, Hu YX, Kattawar GW, Mishchenko MI, Fu Q. 2005. Scattering and absorption property database for nonspherical ice particles in the near- through farinfrared spectral region. Appl. Opt. 44: 5512-5523.

Zhang MH, Lin JL, Cederwall RT, Yio JJ, Xie SC. 2001. Objective analysis of ARM IOP data: Method and sensitivity. Mon. Weather Rev. 129: 309-311. 